\author{
UNIVERSIDADE DE SÃO PAULO \\ FACULDADE DE MEDICINA DE RIBEIRÃO PRETO
}

RODRIGO LACERDA NOGUEIRA

Efeito da variabilidade genética de HPV nos aspectos clínicos da papilomatose respiratória recorrente

RIBEIRÃO PRETO

2016 
RODRIGO LACERDA NOGUEIRA

\section{Efeito da variabilidade genética de HPV nos aspectos clinicos da papilomatose respiratória recorrente}

Tese apresentada à Faculdade de Medicina de Ribeirão Preto da Universidade de São Paulo para obtenção do Título de Doutor em Ciências Médicas.

Área de Concentração: Morfofisiologia de Estruturas Faciais.

Orientadora: Profa. Dra. Fabiana Cardoso Pereira Valera 
AUTORIZO A REPRODUÇÃO E DIVULGAÇÃO TOTAL OU PARCIAL DESTE TRABALHO, POR QUALQUER MEIO CONVENCIONAL OU ELETRÔNICO, PARA FINS DE ESTUDO E PESQUISA, DESDE QUE CITADA A FONTE.

\section{FICHA CATALOGRÁFICA}

Nogueira, Rodrigo Lacerda

Efeito da variabilidade genética de HPV nos aspectos clínicos da papilomatose respiratória recorrente. / Rodrigo Lacerda Nogueira; Orientadora: Fabiana Cardoso Pereira Valera. Ribeirão Preto, 2016.

74p.: 1il.; $30 \mathrm{~cm}$

Tese de Doutorado apresentada à Faculdade de Medicina de Ribeirão Preto/USP. Área de Concentração: Morfofisiologia de Estruturas Faciais.

1. Papilomavirus; 2. Tipo; 3. Variante; 4. Papilomatose recorrente respiratória; 5 . Recidiva; 6 . Neoplasia laríngea. 
Aluno: Rodrigo Lacerda Nogueira

Título: Efeito da variabilidade genética de HPV nos aspectos clínicos da papilomatose respiratória recorrente.

Tese apresentada à Faculdade de Medicina de Ribeirão Preto da Universidade de São Paulo, para a obtenção do título de Doutor em Ciências Médicas.

Área de Concentração: Morfofisiologia de Estruturas Faciais.

Aprovado em:

Banca Examinadora

Prof. Dr.

Instituição:

Assinatura:

Prof. Dr.

Instituição:

Assinatura:

Prof. Dr.

Instituição:

Assinatura:

Prof. Dr.

Instituição:

Assinatura:

Prof. Dr.

Instituição:

Assinatura: 


\section{Dedicatória}

Dedico esta tese à minha esposa Gisela e aos meus filhos Pedro e Mariana. 


\section{Agradecimentos}

Ao meu pai José de Oliveira Nogueira, agradeço por ter me ensinado, por meio de exemplos e não de palavras, desde muito cedo, o mais profundo amor e a dedicação à Medicina.

À minha mãe Maria Virginia Lacerda Homem Nogueira, agradeco por ter inserido em mim a alegria de trabalhar e a vontade de ensinar e aprender todos os dias.

Ao meu irmão Mauricio Lacerda Nogueira, agradeço o exemplo de dedicação na arte da pesquisa.

À Profa. Dra. Fabiana Cardoso Pereira Valera, minha orientadora, agradeço profundamente pela paciência e pelos infinitos ensinamentos que tenho certeza continuarão.

À Profa. Dra. Wilma T. Anselmo-Lima, pelo enorme carinho com que me recebeu nesta casa e pela confiança em mim depositada ao longo desses anos.

À Profa. Dra. Paula Rahal, agradeço por ter viabilizado toda a logística para a confecção dos testes laboratoriais desta tese.

À Rosane Gomes de Paula Queiroz, Bióloga do Laboratório de Biologia Molecular do Serviço de Oncologia Pediátrica do Departamento de Puericultura e Pediatria da Faculdade de Medicina de Ribeirão Preto da Universidade de são Paulo, agradeço pela coleta e pelo armazenamento das amostras deste estudo.

Aos médicos docentes da Divisão de Otorrinolaringologia do Hospital das Clínicas da Faculdade de Medicina de Ribeirão Preto da Universidade de São Paulo. Fazer parte desta equipe é a realização de um sonho e a certeza de que continuarei aprendendo ao longo de minha vida.

Aos médicos contratados da Divisão de Otorrinolaringologia do HCFMRP, agradeço pela amizade e pela oportunidade de trabalhar em um ambiente tão bom e com muito aprendizado. Isto é raro.

Ao Dr. Daniel Salgado Küpper, pela amizade compartilhada nesses anos e pela parceria, tornando nossos ambulatórios em dias de trabalho produtivos e menos pesados. 
Ao amigo otorrinolaringologista Thiago Augusto Damico, pela ajuda na configuração das planilhas.

A todos os residentes e ex-residentes que contribuíram para esta tese (e foram muitos mesmo, sendo impossível citá-los).

À secretária Maria Cecilia Onofre, pela infinita paciência comigo ao longo do doutorado e pelas revisões e formatação desta tese. Muito obrigado mesmo.

Ao Departamento de Otorrinolaringologia da Faculdade de Medicina de São José do Rio Preto (FAMERP), por minha formação humana e na especialidade. A cada dia de minha profissão sou mais grato pelos ensinamentos aí recebidos.

Ao Prof. Dr. José Victor Maniglia, agradeço pela formação, amizade e por ter confiado em mim nos momentos mais difíceis.

Ao Dr. Nobile Cosmos Malago, agradeço o companheirismo, a parceria sincera, os ensinamentos e a disponibilidade na vida real da otorrinolaringologia de Jaboticabal.

Aos meus amigos Jefferson, Fabiano, Ana, Rogério, Eliana e Alexandre, agradeço a amizade verdadeira de 20 anos e os bons momentos que vivemos juntos e, principalmente, os que virão.

Ao meu amigo Fábio Turco, companheiro do sonho da USP, agradeço a amizade e o exemplo de perseverança. Atingimos nossos sonhos em tempos diferentes.

Ao meu amigo Paulinho, agradeço a amizade em todos os momentos.

À minha esposa Gisela, agradeço todos os dias (maravilhosos, bons, ruins, desesperadores) que estivemos juntos ao longo desses 22 anos. Sem você seria impossivel e juntos tenho certeza que a nossa batalha terá um final feliz.

À minha filha Mariana, agradeço a alegria e a felicidade com que você preenche nossas vidas.

Ao meu filho Pedro, agradeço por me ensinar a cada minuto o verdadeiro significado de amar.

A DEUS, por me fortalecer ao longo de toda a minha vida para enfrentar os desafios, por mais intransponíveis que eles pareçam. 
Resumo

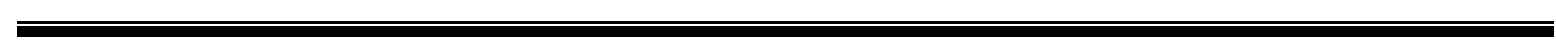


NOGUEIRA, R. L. Efeito da variabilidade genética de HPV nos aspectos clínicos da papilomatose respiratória recorrente. 74f. 2016. Tese (Doutorado). Faculdade de Medicina de Ribeirão Preto-USP. Ribeirão Preto-SP. 2016.

Introdução: A papilomatose recorrente respiratória (PRR) é uma doença benigna de enorme morbidade, com manifestações clínicas muito distintas, causada pelo papiloma vírus humano (HPV) dos tipos 6 e 11. Objetivo: Identificar os diferentes tipos de HPV e suas variantes relacionados com a PRR e estabelecer possível correlação clínica entre o tipo / variante viral e a agressividade da doença. Casuística e Métodos: Estudo prospectivo, realizado com 41 pacientes atendidos no Ambulatório de Laringologia do Hospital das Clínicas da Faculdade de Medicina de Ribeirão Preto da Universidade de São Paulo, entre os anos de 2008 e 2015, que apresentaram quadro de PRR. Foi realizada genotipagem viral das biopsias laríngeas e os vírus presentes foram relacionados com a evolução clínica de cada paciente e a agressividade da doença, pelo escore de Derkay, número de cirurgias e traqueostomia. Resultados: Dos 41 pacientes avaliados, a maioria era do sexo masculino (68,29\%), e maiores de 12 anos (63,41\%). Os menores de 12 anos apresentaram número de cirurgias e escore de Derkay significativamente maiores do que os pacientes mais velhos. Foram identificados somente os HPV dos tipos 6 e 11, na frequência de $73,17 \%$ e $26,83 \%$, respectivamente. A agressividade da doença não mostrou relação com o tipo ou a variante do vírus, mas sim com a idade de apresentação clínica da doença. Conclusão: Os tipos de HPV e as suas variantes não apresentaram comportamento clínico mais agressivo na PRR no grupo estudado. Em contrapartida, a idade foi determinante para a agressividade da doença.

Palavras chave: Papilomavírus, Tipo, Variante, Papilomatose recorrente respiratória, Recidiva, Neoplasia laríngea. 
Abstract 
NOGUEIRA, R. L. Effect of HPV genetic variability on the clinical aspects of recurrent respiratory papillomatosis. 74f. 2016. Tese (Doutorado). Faculdade de Medicina de Ribeirão Preto-USP. Ribeirão Preto-SP. 2016.

Introduction: Recurrent respiratory papillomatosis (RRP) is a benign disease of enormous morbidity that presents very distincts clinical manifestations. It is usually caused by the human papillomavirus (HPV), mostly types 6 and 11. Purpose: To identify the different HPV types and variants related to RRP and to establish a possible correlation between HPV type/variant and viral disease aggressiveness. Casuistic and Methods: This prospective study included 41 patients followed at the Outpatient Clinic of Laryngology of the Medical School of Ribeirão Preto, University of São Paulo, between 2008 to 2015, due to RRP. Virus genotyping was performed on laryngeal biopsies by PCR, and this information was associated to each patient's data regarding aggressiveness of the disease and clinical evolution, by Derkay's score, number of surgeries and tracheostomy. Results: Most patients were male (68.29\%) and older than 12 years-old (63.41\%). Patients younger than 12 years had a significantly higher number of surgeries and Derkay score than older patients. In all samples, only HPV 6 and HPV 11 were detected, in a prevalence of $73.17 \%$ and $26.83 \%$, respectively. The aggressiveness of the disease was not related to the type or variant of the virus, but to the age of patient when the clinical presentation of the disease occurred. Conclusions: HPV types and variant of HPV showed no more aggressive clinical behavior in recurrent respiratory papillomatosis in the studied group. In contrast, age was crucial to the aggressiveness of the disease.

Keywords: Papillomavirus, Type, Variant, Recurrent respiratory papillomatosis, Recurrence, Benign tumor. 
Lista de Figuras 
Figura 1- Genoma do HPV-16, protótipo da família Papillomaviridae, evidenciando a região regulatória (LCR), as regiões precoces (E1 a E7) e as tardias (L1 e L2). (Adaptado de Derkay et al., 2004). ......23

Figura 2 - Número de cirurgias vs idade dos pacientes...................................41

Figura 3 - Escore de Derkay vs idade dos pacientes .................................... 42

Figura 4 - Número de cirurgias vs tipos de HPV ............................................4 43

Figura 5 - Escore de Derkay vs tipos de HPV ……........................................ 45

Figura 6 - Número de cirurgias vs HPV 6, variante e não variante ......................46

Figura 7 - Escore de Derkay vs HPV 6, variante e não variante.........................47 
Lista de Abreviaturas 
PRR- $\quad$ Papilomatose respiratória recorrente

HPV- $\quad$ Papilomavírus humano (do inglês human papillomavirus)

LCR- Regiao de controle longo (do inglês Long control region)

CDC- $\quad$ Centro de Controle e Prevenção de Doenças

HCFMRP-USP- Hospital das Clínicas da Faculdade de Medicina de Ribeirão Preto da Universidade de São Paulo 


\section{SUMÁRIO}

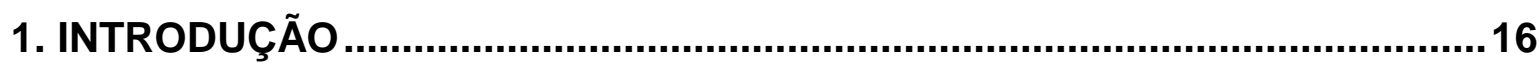

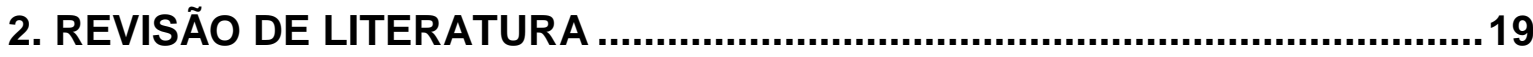

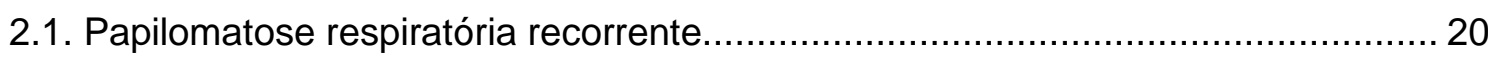

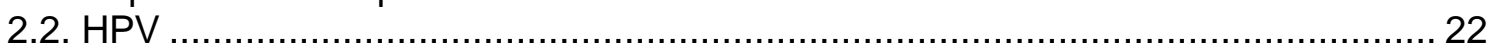

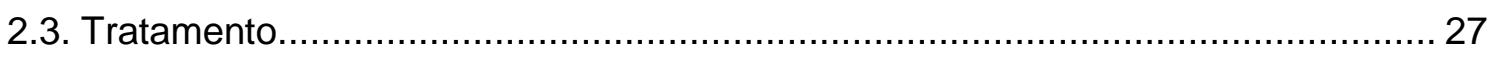

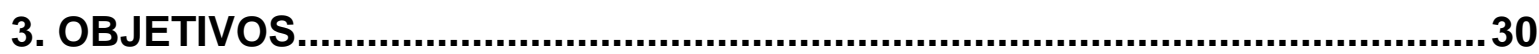

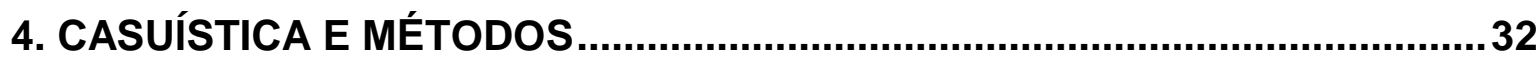

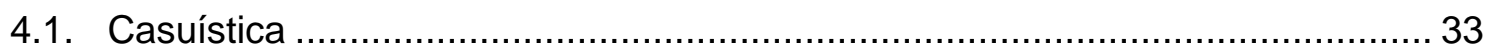

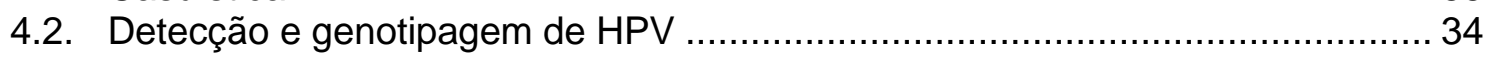

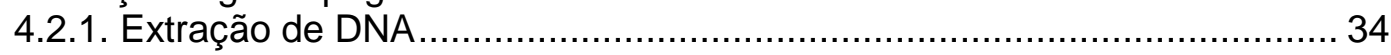

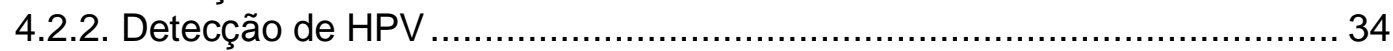

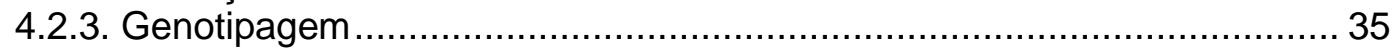

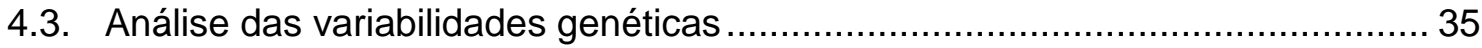

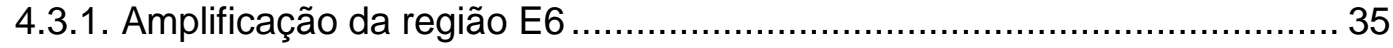

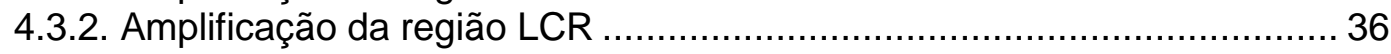

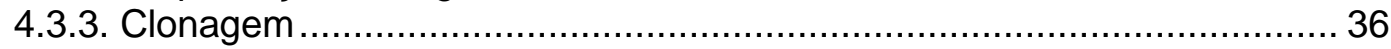

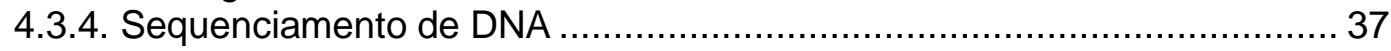

4.3.5. Análise da estrutura secundária in silico ............................................... 38

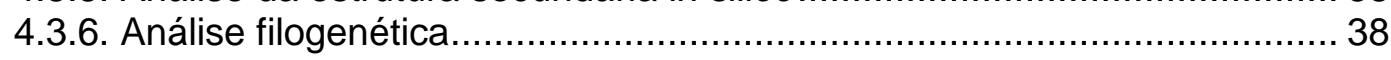

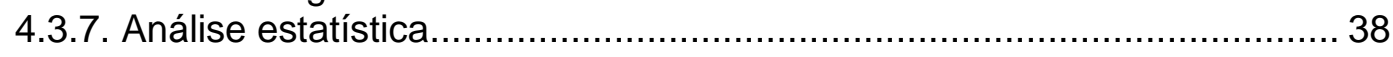

5. RESULTADOS

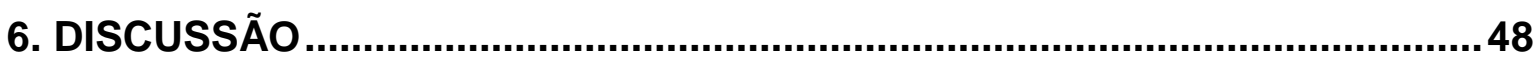

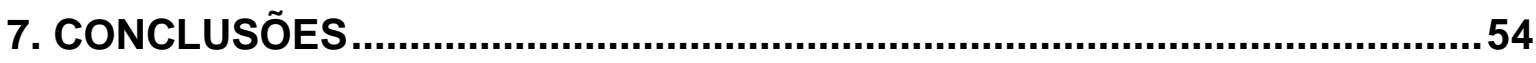

8. REFERÊNCIAS BIBLIOGRÁFICAS........................................................56

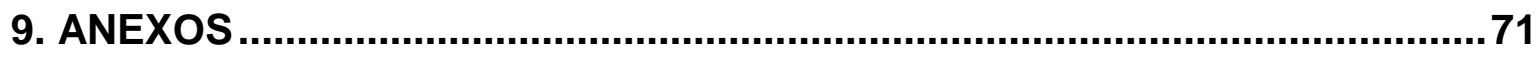


1- Introdução 
A papilomatose respiratória recorrente (PRR) foi inicialmente descrita no final da década de 1800 por Sir Morrell Mackenzie (1837-1892) (Goon et al., 2008). É uma doença recorrente, em geral benigna, caracterizada pela formação de lesões proliferativas exofíticas (papilomas) no tecido conectivo coberto por epitélio. É também conhecida como papilomatose laríngea ou papilomatose glotal (Carifi et al., 2015). Geralmente, é limitada à laringe (Reeves et al., 2003), mas papilomas podem se estender para a árvore traqueobrônquica e o parênquima pulmonar (Rad et al., 2007; Gélinas et al., 2008), ou ainda para a faringe.

A PRR apresenta distribuição etária bimodal. O primeiro grupo de pacientes é acometido abaixo dos 12 anos, sendo essa forma, também conhecida como juvenil, a mais comum; e o segundo acima dos 12 anos, sob a forma conhecida como adulta (Prince et al., 2002; Larson; Derkay, 2010). Em crianças, a contaminação pelo HPV pode ocorrer via transmissão vertical intrauterina ou durante o trabalho de parto normal (Niyibizi et al., 2014).

A incidência de PRR nos Estados Unidos é de 4,3 casos novos por 1000 crianças e 1,8 casos por 1000 adultos (Derkay; Wiatrak, 2008; Goon et al., 2008). No Brasil, essa incidência é desconhecida. Em crianças, a PRR é o tumor laríngeo benigno mais comum e a segunda causa mais importante de disfonia (Derkay; Wiatrak, 2008).

Clinicamente, a PRR caracteriza-se por disfonia, dispneia, estridor, infecções respiratórias recorrentes do trato aéreo superior, pneumonias, disfagias e deficiências no crescimento (Derkay; Wiatrak, 2008; Carifi et al., 2015). Há piora progressiva do padrão vocal, podendo evoluir, nos casos mais avançados, para obstrução da via aérea. Os sintomas tendem a ser mais agressivos nas crianças em virtude do rápido crescimento das lesões associado às características peculiares da laringe infantil com sua via aérea diminuta, requerendo muitas intervenções cirúrgicas devido a sintomas de obstrução das vias aéreas. Outra característica importante da doença é a recidiva das lesões. As recorrências têm sido motivo de grande frustração na área médica há várias décadas, sendo considerada de difícil controle na otorrinolaringologia (Done; Clarke, 2010).

Apesar de já descrita desde o século XIX, foi somente na década de 1980 que se estabeleceu a etiologia viral dessa doença com a identificação do vírus 
papiloma humano (human papillomavirus, HPV) (Mounts et al., 1982; Bennett; Powell, 1987; Dickens et al., 1991). Nas últimas décadas, vários estudos evidenciaram aumento significativo dos casos de tumor de orofaringe associado à infecção pelo HPV (D'Souza et al., 2007). Outro fator determinante no desenvolvimento e na agressividade dessa patologia são as variabilidades genotípicas do HPV (Donne et al., 2010). 
2. Revisão de Literatura 


\subsection{Papilomatose respiratória recorrente}

A PRR pode ser um perigo à vida do paciente, mesmo sendo histologicamente benigna (Carifi et al., 2015). Segundo Derkay (2001), cerca de 1500 a 2500 novos casos de PRR ocorrem a cada ano nos Estados Unidos da América. Silverberg et al. (2003) encontraram incidência de PRR em 6,9 casos por 1000 nascimentos em mães que apresentavam lesões genitais durante a gestação, contra nenhum caso em crianças de mães sem lesões. Dessa forma, esses autores observaram que crianças nascidas de mães com lesões genitais ativas durante a gravidez apresentavam risco 231,4 vezes maior de ter PRR.

Outros fatores como más condições de higiene pessoal, não uso de preservativos, associação de sexo com drogas, álcool e cigarro têm sido relatados como fatores de risco importantes para infecção por HPV com consequente desenvolvimento da papilomatose (Winer et al., 2003). Além desses, alguns autores apontam também como fatores de risco específicos para a forma juvenil da PRR: parto normal, mãe de baixo nível socioeconômico, ser primogênito, e idade materna inferior a 20 anos (Derkay et al 1995; Shah et al., 1998; Silverberg et al., 2003).

Apesar do grande número de pessoas contaminadas pelo HPV, somente uma pequena parcela da população é acometida pela PRR. Inúmeros fatores poderiam estar relacionados com este fato: tipo viral, variantes do vírus, carga viral, infectividade do vírus, susceptibilidade do hospedeiro, imunidade, coinfecção viral, tempo de exposição ao vírus, doenças associadas, entre outros (Bucninsk et al., 2008).

Clinicamente, a doença caracteriza-se por disfonia, estridor, dispneia e em casos mais graves por insuficiência respiratória (Derkay, 2001). O diagnóstico é realizado por meio da visualização das lesões por videolaringoscopia.

A PRR tem dois picos de prevalência: o primeiro, entre dois e cinco anos de idade, e outro entre 20 e 40 anos. No estudo de Reeves et al. (2003), a idade média para o diagnóstico foi de quatro anos, e as crianças demandavam média de 5,1 cirurgias por ano após o dignóstico de papilomatose, para controle clínico da mesma. Aproximadamente $75 \%$ dos casos de PRR juvenil manifestam-se 
clinicamente antes de a criança atingir cinco anos de idade (Mounts; Kashima, 1984; Kashima et al., 1992).

Quando a papilomatose se manifesta mais precocemente, a doença normalmente apresenta-se mais agressiva (Wiatrak et al., 2004; Derkay; Wiatrak, 2008). Essa maior agressividade, associada à anatomia peculiar da criança, com sua via aérea estreita, cursa com maior necessidade de traqueostomia de urgência, antes mesmo do primeiro diagnóstico. Um estudo realizado com pacientes que apresentavam papilomatose laríngea recorrente grave demonstrou que nenhum adulto necessitou de traqueostomia, porém $60 \%$ das crianças necessitaram ser traqueostomizadas (Avelino; Pontes, 2016). Além disso, outro fator preocupante é a possibilidade de transformação maligna dos papilomas laríngeos, relatada numa frequência de cerca de 3 a $7 \%$ dos casos por Aaltonen et al. (2002); e que pode ocorrer, inclusive, em genótipos de HPV considerados de "baixo risco", ou seja, com menor potencial de desenvolvimento tumoral (Lin et al., 2010). O HPV-26, um tipo de baixo risco, é encontrado apenas em câncer cervical, como o carcinoma de laringe (Muenscher et al., 2009). A caracterização do genótipo viral associado à PRR é essencial para o melhor entendimento da patogênese tumoral.

Além da menor idade, outro fator que parece estar relacionado à maior gravidade do PRR é o tipo de HPV. Entretanto, a literatura é controversa quanto a esse tópico. Apesar de a maioria dos estudos relatar suposta maior agressividade do HPV-11 (Reeves et al., 2003; Wiatrak et al., 2004), outros estudos recentes apresentaram resultados divergentes, como o de Tjon Pian Gi et al. (2015), que observaram que pacientes adultos infectados pelo HPV 6 apresentaram perfil de maior agressividade, com doenças mais recorrentes. Outro fator muito preocupante é a disseminação do vírus pela árvore traqueobrônquica, evoluindo para papilomatose pulmonar, o que resulta, muitas vezes, em uma doença incontrolável e fatal (Kimberlin, 2004). Omland et al. (2014) mencionaram que esses casos são mais comumente associados ao HPV 11.

Além dos fatores acima citados, outros podem exercer papel determinante na progressão da PRR, como as variantes do genótipo do HPV, responsável pela infecção. Nos últimos anos, os estudos sobre essas variantes têm recebido 
atenção especial da comunidade científica. No entanto, não existem ainda pesquisas que avaliem a associação entre essas variantes e a agressividade da PRR. Assim, em virtude de a manifestação clínica da PRR ser tão heterogênea nas diferentes faixas etárias, inúmeros esforços vêm sendo empregados ao longo dos anos para melhor entendimento do comportamento dessa doença.

\subsection{HPV}

Os HPVs são vírus epiteliotrópicos pertencentes à família Papillomaviridae. O vírion é composto por um capsídeo não-envelopado de cerca de $60 \mathrm{~nm}$ de diâmetro, com 72 pentâmeros, de simetria icosaédrica. O genoma é constituído de uma dupla fita circular de DNA de cerca de $8 \mathrm{~kb}$, associado a histonas celulares em um complexo similar à cromatina. Codifica entre oito e dez ORFs (open reading frames, janelas abertas de leitura) (Mcmurray et al., 2001; Terai; Takagi, 2001), divididos em três regiões: região regulatória (long control region, LCR), precoce (E1 a E7) e tardia (L1 e L2) (Figura 1). 


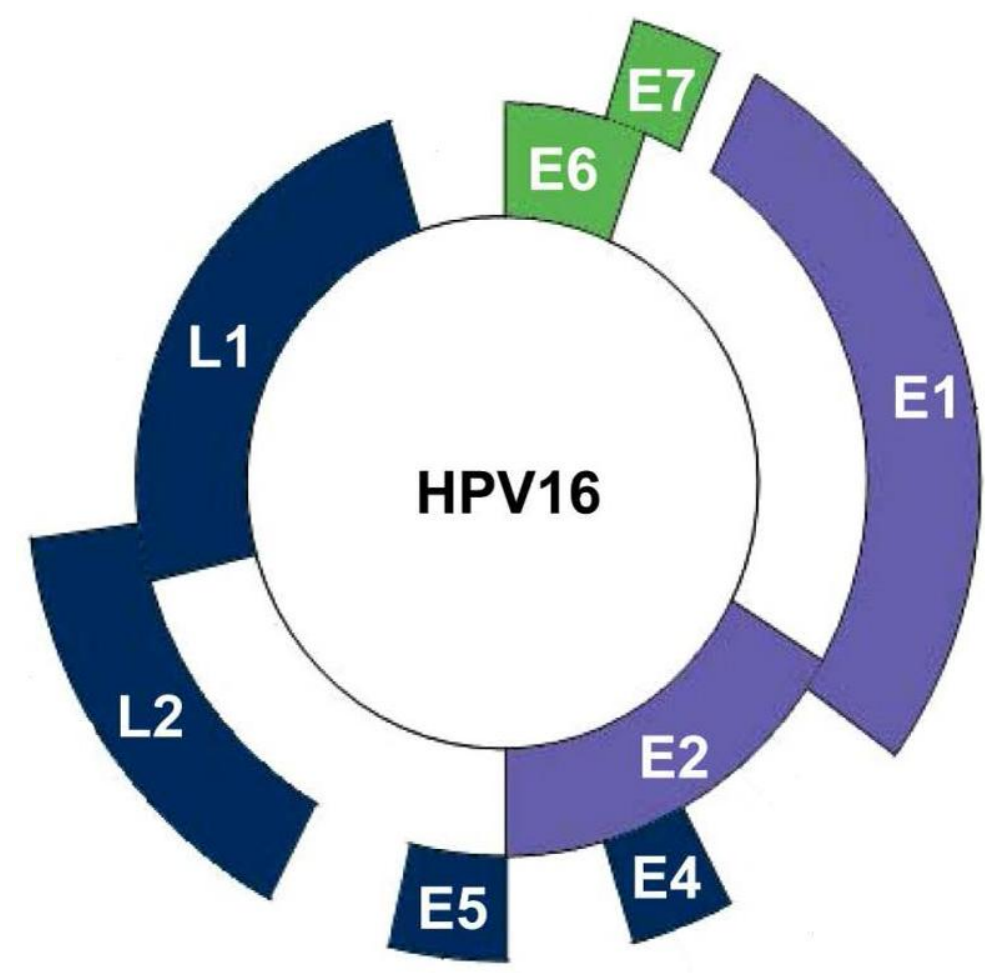

Figura 1: Genoma do HPV-16, protótipo da família Papillomaviridae, evidenciando a região regulatória ( $L C R)$, as regiões precoces (E1 a E7) e as tardias (L1 e L2). (Adaptado de Derkay et al., 2004).

A interação de fatores celulares do hospedeiro com a região $L C R$ do genoma do HPV induz a transcrição dos genes precoces virais (E1 a E7), que por sua vez, codificam as proteínas necessárias à sua replicação. As proteínas E1 e E2 formam um complexo em torno da origem de replicação (Fehrmann; Laimins, 2003). A E2 é um repressor do promotor viral precoce, funcionando como controle no mecanismo de replicação (Howley et al., 2013). A E4 é expressa como uma proteína que se funde a cinco aminoácidos da região N-terminal da E1 (fusão E1E4) e parece estar envolvida em alterações da rede do citoesqueleto (Doorbar et al., 1991). As proteínas E5 induzem a proliferação celular programada, inibem a apoptose e podem ativar os receptores do fator de crescimento e outras proteínas quinases (larc, 2007). As proteínas E6 e E7 são consideradas oncoproteínas, ou seja, são responsáveis pela transformação maligna causada por genótipos do HPV de alto risco e atuam na modulação de atividades de proteínas celulares que 
regulam o ciclo celular (Werness et al., 1990). Os genes tardios L1 e L2 codificam as proteínas do capsídeo viral (Schoell et al., 1999).

A ação oncogênica do HPV parece estar relacionada a interferências em mecanismos importantes que controlam a proliferação celular. As oncoproteínas virais E6 e E7 são as mais importantes nesse processo, pois são capazes de se ligar às proteínas p53 e pRb, respectivamente, e interferirem em suas funções normais (Terai; Takagi, 2001).

Mais de 200 genótipos de HPVs são conhecidos e estes podem ser clinicamente divididos em HPVs de alto ou de baixo risco, com base na sua associação com o desenvolvimento de tumores. Os HPVs de baixo risco, como HPV-6 e HPV-11 estão relacionados ao surgimento de neoplasias benignas da mucosa das cavidades oral-nasal, faringe, laringe ou trato genital. Já os HPVs de alto risco, como os tipos 16 e 18, relacionam se a lesões malignas, geralmente na região anorretal (Mounts et al., 1982; Abramson et al., 1987; Collins et al., 1988; Choi; Park, 2016).

O HPV é um vírus sexualmente transmissível, comum entre adolescentes e adultos (Muñoz, 2000). Entretanto, pode ser transmitido verticalmente de mãe para filho no período perinatal (Rice et al., 1999; Minkoff; Chervenak, 2003) e a possibilidade de transmissão por essa via está associada à carga viral no trato genital de mulheres infectadas pelo HPV (Puranen et al., 1997; Cason et al., 1999).

Entre os adultos, o papilomavírus passou a ser identificado com mais frequência na mucosa oral, possivelmente devido ao aumento da prática do sexo oral (Kellokoski et al., 1990). Porém, não se descarta a possibilidade de contaminação em procedimentos cirúrgicos e ao nascimento, com permanência do vírus latente até a idade adulta (Kashima et al., 1992; Snoeck et al., 1998; Derkay, 2001).

O Centro de Controle e Prevenção de Doenças (CDC) estima que até a sexta década de vida, pelo menos $80 \%$ das mulheres terão infecção genital por HPV. No Brasil, o Instituto Adolfo Lutz realizou testes de captura de híbridos para HPV usando amostras randomizadas e registrou em São Paulo taxa de 16,4\% de infecção pelo HPV de alto risco em uma população normal com mulheres 
assintomáticas, mostrando tendência de alta prevalência de infecção por HPV em mulheres da população geral. Esse mesmo estudo realizou outro teste com mulheres previamente triadas, potencialmente portadoras de lesões de colo uterino, e o grau de positividade para HPV de alto risco subiu para 57,9\% (Pereira et al., 2003). Derkay (2001) encontrou incidência de infecção pelo HPV em 43\% das mulheres jovens com vida sexual ativa.

A relação causal entre HPV e PRR começou a ser desvendada em 1923 por Ullmann, quando este identificou a presença do HPV após injetar em seu próprio braço amostra obtida em laringe e consequente aparecimento de lesões papilomatosas (Ullmann, 1923). A partir desse estudo, a confirmação da presença do HPV em lesões foi aumentando à medida que as técnicas laboratoriais foram se aprimorando. Com o uso da reação em cadeia da polimerase em tempo real (PCR), o HPV passou a ser identificado em 100\% dos casos (Smith et al., 1993; Draganov et al., 2006).

Os tipos de HPV são classificados pelo genótipo, definidos pela sequência do gene L1 (de Villers, 1997), porque essa região engloba a proteína capsulada e se apresenta com grande estabilidade (Bernard et al., 1994). Na PRR, os genótipos mais comumente encontrados são os HPV-6 (50 a 84\% dos casos) e HPV-11 (25 a 37\% dos casos).

A cronicidade e a recorrência da PRR talvez esteja relacionada à persistência de HPV no hospedeiro (Velyvyte et al., 2002). Kocjan et al. (2013) genotiparam os papilomas das lesões laríngeas em biopsias consecutivas dos pacientes por um período de 22 anos e verificaram a presenca do mesmo genótipo de papiloma no decorrer desse longo período. Esse estudo reforça a hipótese de que as recidivas da doença ocorrem em consequência da longa persistência de um único tipo de HPV, e não de diferentes infecções com novos tipos de HPV.

Rabah et al (2001) avaliaram 61 pacientes com PRR. Nesse estudo, o HPV-11 foi o tipo viral mais comum entre crianças mais jovens (três anos) afroamericanas e o curso da doença apresentou-se mais ativo e agressivo nessas crianças, com longos períodos de recidiva. Da população de estudo, 5\% (3/61) desenvolveram papilomatose traqueobrônquica e evoluíram para carcinoma 
brônquico. Os autores concluíram que o genótipo do HPV-11 confere caráter mais agressivo à PRR.

Assim, nas últimas décadas, inúmeros estudos evidenciaram suposta maior agressividade do HPV-11 (Intakorn, 2014; Blackledge; Anand, 2000; Cook et al., 2000; Wiatrak et al., 2004). Entretando, ultimamente, alguns autores vêm questionando essa afirmação. Buchinsky et al. (2008) afirmam que a idade seria o fator mais importante para se determinar a agressivade da PRR, e não o tipo viral. Já Tjon Pian Gi et al. (2015) encontraram maior agressividade do HPV-6 em adultos. Gaboot et al. (1997) e Peñaloza-Plascencia et al. (2000) também identificaram maior agressividade do HPV-6. Ainda, o HPV-6 está relacionado à transformação maligna com acometimento pulmonar (Dilorenzo et al., 1992), em tonsilas (Bercovich et al., 1991) e laríngeo (Venutti et al., 2000).

Os tipos de HPV são determinados quando os genomas da região L1 diferem entre si em pelo menos $10 \%$. Já as variantes do HPV são definidas a partir da diferenciação genômica entre 2 e 10\% (Bernard et al., 2010). Mounts et al. (1982) descreveram a primeira variante do HPV.

As variantes genômicas de HPV-6 são classificadas em sua relação à sequência protótipo, chamada de HPV-6b, que foi isolada de um condiloma acuminado (Gissmann; zur Hausen, 1980; de Villiers et al., 1981; Kovelman et al., 1999). Assim, têm-se as variantes genômicas relacionadas ao HPV-6b e as associadas aos HPV-6a/6vc (Heinzel et al., 1995). A sequência protótipo de HPV11 veio de uma amostra de papiloma laríngeo de 1982, determinada por Southern Blot e foi completamente sequenciada em 1986 (Gissmann et al., 1982; Dartmann et al., 1986). As variantes de HPV podem diferir em sua patogenicidade e oncogenicidade (Chan et al., 2013; Cornet et al., 2013).

Outro fator complicador reside na complexa interação do vírus com hospedeiros geneticamente distintos (de Araújo Souza et al., 2009) e na prevalência da circulação de HPVs variantes em diferentes populações e regiões geográficas distintas (Xi et al. 2006).

A variabilidade de agressividade clínica da PRR com diferentes respostas aos inúmeros tratamentos propostos poderia estar relacionada à virulência das variantes do HPV (Mounts et al., 1982; Donne et al., 2010). Entretanto, poucos 
estudos foram realizados no Brasil para se determinarem as variantes do HPV-6 e -11 na PRR, tanto na forma adulta como juvenil, e não existem pesquisas que tenham relacionado a presença dessas variantes à agressividade da doença.

\subsection{Tratamento}

O tratamento da papilomatose, ainda nos dias atuais, consiste em grande desafio médico. Vários estudos têm buscado a melhor opção terapêutica para a PRR. No geral, existe a constante cirúrgica (apesar de variabilidade nos métodos, como material a frio, diferentes tipos de laser, ou uso de microdebridadores) associada ou não a medicações adjuvantes como o cidofovir, interferon $\alpha$, antivirais (Pransky et al., 2000; Wilson et al., 2000) e, mais recentemente, as vacinas tetravalentes (Hermann et al., 2016). Nikolopoulus (2013) reforçou a dificuldade do tratamento da PRR na sua revisão sistemática, evidenciando a falha dos tratamentos adjuvantes no controle dessa doença.

Classicamente, o tratamento cirúrgico é realizado com instrumentos frios. Nas últimas décadas, o laser passou a ser utilizado por vários serviços. Entretanto, com a disseminação dessa técnica inúmeras complicações foram observadas, como lesões térmicas da via aérea, cicatrizes e estenose da laringe, além de fístulas traqueoesofágicas (El-Bitar; Zalzal, 2002, Pasqualle et al., 2003). Em contrapartida, nos últimos anos, o uso do microdebridador vem avançando devido as suas vantagens: ser menos agressivo, menor número de complicações, melhor controle sobre o tecido normal, além de ser mais acessível por seu menor custo (Patel et al., 2003; Lee, 2005; Avelino et al., 2013).

O interferon foi uma das primeiras medicações adjuvantes utilizadas no tratamento da PRR, embora seu mecanismo de ação seja desconhecido e sua eficácia contestada (Leventhal et al., 1988). Foi, geralmente, indicado em casos graves com disseminação pulmonar, porém seus efeitos colaterais limitam muito o seu uso (fadiga, febre, náusea, elevação de transaminases, leucopenia e trombocitopenia). Além disso, alguns autores contestam a eficácia dessa droga para o controle da recidiva dessas lesões (Gallagher; Derkay, 2009). Já King et al. 
(2013), fizeram uso tópico de interferon a e sugeriram que dessa forma a droga parece ser eficaz e apresenta poucos efeitos colaterais nos pacientes com PRR. Porém, mais estudos serão necessários para confirmar essa hipótese.

Desde 1998, o cidofovir tem sido utilizado como medicação adjuvante no tratamento da PRR. Esse medicamento recebeu, na época, especial atenção da comunidade científica, uma vez que foi considerado uma droga promissora para o tratamento da doença (Chung et al., 2006; Dikkers, 2006; Naiman et al., 2006; Pontes et al., 2006; Pudszuhn et al., 2007). No entanto, seu mecanismo de ação na papilomatose ainda é incerto. Na maioria dos estudos a terapia com aplicação intralesional do cidofovir, após a retirada das lesões, sugeriu ser efetiva, com regressão dos papilomas e aumento do intervalo necessário entre as cirurgias (Donne et al, 2008; Fusconi et al., 2014; Wilcox et al., 2014). Essa droga apresenta alto custo e está relacionada a baixo índice de efeitos colaterais, apesar da preocupação com relação ao seu potencial de carcinogenicidade (Dikkers, 2006). Embora haja grande número de serviços utilizando cidofovir, não existe um protocolo estabelecido quando à dose, frequência e concentração dessa medicação. Derkay et al. (2013) sugeriram a adoção de concentração similar da droga em adultos e crianças com variações de 2,5 a 7,5 mg/mL com dose máxima de $3 \mathrm{mg} / \mathrm{kg}$. No entanto, Chadha e James (2012), em seu estudo de revisão sistemática, não conseguiram evidenciar a eficácia do cidofovir como terapia adjuvante para a PRR.

Atualmente, outra droga vem sendo muita estudada, o Bevacizumab (Avastin $($ ) ), uma imunoglobulina monoclonal recombinante que inibe o fator de crescimento vascular endotelial, um importante fator para o desenvolvimento da PRR (Best et al., 2012; Mohr et al., 2014; Sidell et al., 2014). O uso dessa medicação associado ao laser de KTP tem sido considerado, nos últimos anos, como o tratamento mais promissor da papilomatose laríngea (Ramet et al., 2011; Zeitls et al., 2011).

Além desses tratamentos, a vacinação contra HPV parece ter potencial para auxiliar na prevenção da PRR. Atualmente, existem duas vacinas para HPV disponíveis comercialmente: Gardasilß para os tipos -6, -11, -16 e -18, e Cervarix $^{\mathrm{TM}}$ para os tipos -16 e -18 . Essas vacinas foram desenvolvidas para 
proteção ao carcinoma de colo uterino, porém há a possibilidade de proteger também outros carcinomas, se os tipos de HPV forem os mesmos cobertos por elas (Derkay; Wiatrak, 2008; Goon et al., 2008). Ainda, ao menos teoricamente, acredita-se que a vacinação em massa, num futuro próximo, poderia conferir imunidade à população com consequente diminuição da incidência da PRR.

Existem relatos de uso da vacina como tratamento da papilomatose, porém os resultados são controversos. Förster et al. (2008) e Mudry et al. (2011) relataram casos isolados de pacientes com melhora significativa após o uso da vacina. Hočevar-Boltežar et al. (2014) observaram melhora da agressividade da doença em pacientes adultos, com aumento do intervalo entre as cirurgias após o uso da vacina tetravalente. Entretanto, em recente estudo, Hermann et al. (2016) avaliaram a eficácia da vacina no curso da doença em dezessete pacientes infantis e não encontraram diferenças na clínica da doença antes e após a vacinação. Já Tjon Pian Gi et al. (2016) observaram, pela primeira vez, elevação significativa nos níveis de anticorpos em pacientes com PRR após a terceira dose da vacina em relação aos níveis pré-vacinação. Entretanto, esse estudo foi realizado somente em seis pacientes.

Estudos que abordam a variabilidade genética do HPV são relevantes, visto que o HPV é importante na gênese da PRR, além de estar associado ao maior risco de desenvolvimento de lesões malignas da laringe (Sand et al., 2000; Smith et al., 2000).

Devido à morbidade da PRR, grande importância e atenção devem ser dispensadas aos HPVs, a fim de se entender melhor sua patogenicidade e infectividade. Nesse contexto, este estudo se justifica pela necessidade de se identificarem os tipos e as variantes de HPVs envolvidos na patogênese e, assim, se estabelecerem terapias mais adequadas às infecções e lesões causadas por esse vírus. 
3. Objetivos

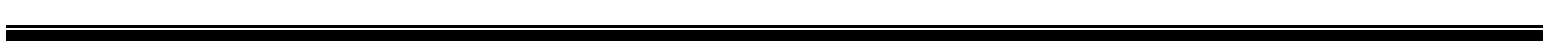


Os objetivos deste estudo foram:

- Identificar os tipos de HPV e suas formas variantes em PRR;

- Estabelecer correlação clínica entre os tipos / variantes virais e a agressividade da PRR, por meio da extensão da lesão e do número de recidivas;

- Observar a influência da idade na agressividade da doença. 
4. Casuistica e Métodos 


\subsection{Casuística}

Este estudo prospectivo de coorte foi realizado entre os anos 2008 e 2015, com pacientes atendidos no Ambulatório de Laringologia do Hospital das Clínicas da Faculdade de Medicina de Ribeirão Preto da Universidade de São Paulo (HCFMRP-USP). Foram selecionados todos aqueles que clinicamente apresentassem disfonia, estridor e/ou dispneia, e que o exame de videolaringoscopia fosse condizente com PRR, independente da idade. O exame de videolaringoscopia foi realizado de rotina para todos os pacientes, para elucidação diagnóstica e estadiamento clínico por meio da escala de Derkay (Anexo A). A escala de Derkay avalia a intensidade dos sintomas, e principalmente a presença e extensão de lesões em relação aos sítios anatômicos acometidos por elas.

Após o diagnóstico clínico de PRR, os pacientes foram encaminhados para o procedimento cirúrgico. Todas as cirurgias foram realizadas em centro cirúrgico sob anestesia geral, sendo empregada a técnica cirúrgica com utilização de instrumentos frios e aplicação de cidofovir (na concentração de $75 \mathrm{mg} / \mathrm{mL}$, respeitando-se a dose máxima de $1 \mathrm{mg} / \mathrm{kg}$ ) no leito cirúrgico após a retirada das lesões.

Nos pacientes que aceitaram participar da pesquisa (ou em caso de menores, após concordância de um dos pais ou dos responsáveis), amostras do papiloma foram colhidas durante o procedimento cirúrgico. Essas amostras foram divididas e encaminhadas ao Serviço de Patologia do HCFMRP-USP para confirmação diagnóstica, armazenadas em Trizol a $-80^{\circ} \mathrm{C}$ e, posteriormente, encaminhadas ao Laboratório de Estudos Genômicos do IBILCE-UNESP em São José do Rio Preto SP.

Também como rotina do serviço, os pacientes operados foram acompanhados por meio de avaliações clínicas e realização sistemática de videolaringoscopias. Durante a evolução clínica, os casos de recidiva das lesões com piora clínica foram novamente indicados para outro procedimento cirúrgico. A cada momento cirúrgico, um novo escore de Derkay foi realizado. Esses dados foram avaliados em todos os pacientes cujas biópsias foram colhidas, e os dados 
clínicos compilados em planilha do programa Excel para, posteriormente, serem correlacionados com os dados laboratoriais.

Este estudo foi aprovado pelo Comitê de Ética em Pesquisa do HCFMRPUSP de acordo com o processo no 11227/2008 (Anexo B) e todos os pacientes e/ou seus responsáveis que concordaram em participar da pesquisa, após esclarecidos, assinaram o Termo de Consentimento Livre e Esclarecido (Anexo C).

\subsection{Detecção e genotipagem do HPV}

\subsubsection{Extração de DNA}

O DNA das biópsias foi extraído utilizando-se o QIAamp DNA Micro Kit (Qiagen), seguindo-se as instruções do fabricante. A qualidade do DNA foi verificada por PCR do gene endógeno GSTP1.

\subsubsection{Detecção de HPV}

A detecção de HPV nas biópsias foi realizada por PCR, conforme descrito anteriormente, utilizando-se os sets de oligonucleotídeos iniciadores genéricos PGMY09/11 que amplificam um segmento de 450 bp na região L1 de grande gama de genótipos de HPV (Gravitt et al., 2000). Para a reação foram adicionados 2,5 $\mathrm{U}$ de High Fidelity Enzyme Mix (Fermentas), 2,5 $\mathrm{LL}$ de High Fidelity PCR Buffer 10x, 4,0 mM de $\mathrm{MgCl}_{2}, 0,2 \mathrm{mM}$ de cada dNTP, 0,32 mM de cada oligonucleotídeo iniciador, $80 \mathrm{ng}$ de DNA e $\mathrm{H}_{2} \mathrm{O}$ livre de nuclease para o volume final de $25 \mu \mathrm{L}$. A reação foi submetida a um passo inicial de desnaturação a $95^{\circ} \mathrm{C}$ por $13 \mathrm{~min}$, seguido por 40 ciclos de 1 min a $95^{\circ} \mathrm{C}, 1$ min a $55^{\circ} \mathrm{C}$ e $1 \mathrm{~min}$ a $72^{\circ} \mathrm{C}$, seguidos por uma fase final de extensão de $72^{\circ} \mathrm{C}$ por $5 \mathrm{~min}$. Cinco microlitros foram aplicados no gel de agarose 1,5\% e corados com brometo de etídeo, para visualização dos fragmentos amplificados. 


\subsubsection{Genotipagem}

A genotipagem dos HPVs encontrados nas biópsias foi realizada por ensaio de polimorfismo de tamanho de fragmentos de restrição (restriction fragment length polymorphism, RFLP), conforme mapa descrito na literatura (Bernard et al., 1994). Resumidamente, após amplificação das amostras por PCR, as mesmas foram digeridas independentemente por sete enzimas de restrição (BamHI, Ddel, Haell, Hinfl, Pstl, Rsal e Sau3al).

Para cada amostra, foram utilizados sete tubos contendo $10 \mu \mathrm{L}$ de produto da reação de PCR e $10 \mu \mathrm{L}$ de tampão (100 mM de $\mathrm{NaCl}, 10 \mathrm{mM}$ de $\mathrm{MgC1}$, 10 mM de TRIS (pH 7.5) e 10 mM de $\beta$-mercaptoetanol). A cada tubo foi adicionado uma enzima de restrição e o resultado foi visualizado em gel de poliacrilamida a 10\%. O padrão de restrição de cada amostra foi, então, comparado com os padrões de restrição descritos por Bernard et al. (1994).

\subsection{Análise das variabilidades genéticas}

Para a análise de variabilidade genética foram amplificadas a região genômica de E6 e a LCR das amostras positivas de HPV-6 e -11, utilizando-se oligonucleotídeos iniciadores específicos.

\subsubsection{Amplificação da região E6}

Para amplificação da região E6 foram utilizados os oligonucleotideos específicos para HPV-6 (HPV6-E6F, GGGGGATCCGAATTCATGGAAAGTGCAAATGC e HPV6-E6R, GTGAAGCTTGGATCCTAGGGTAACATGTCTTCC) e para HPV-11 (HPV11-E6F, AAAATTAGCAGACGAGGCATT e HPV11-E6R, CCACCTTGTCCACCTCATCT).

A reação de amplificação consistiu de 6,0 U de High Fidelity Enzyme Mix, (Fermentas), $5 \mu \mathrm{L}$ de 10X High Fidelity PCR Buffer, 1,5 mM de $\mathrm{MgCl}_{2}, 0,24 \mathrm{mM}$ de dNTPs, 0,4 mM de cada oligonucleotídeo iniciador, 500 ng de DNA e $\mathrm{H}_{2} \mathrm{O}$ livre de nucleases q.s.p., com volume final de 50,0 $\mu \mathrm{L}$. A reação consistiu de uma fase de desnaturação de 5 min a 95ํㅡ, seguida por 35 ciclos de 1 min a 95ำ, 1 min a 
$5^{\circ} \mathrm{C}$ e 1 min a $72^{\circ} \mathrm{C}$, seguidos por uma fase final de extensão de $72^{\circ} \mathrm{C}$ por 8 min. Os produtos de PCR foram submetidos à eletroforese em gel de agarose $1 \% \mathrm{e}$ corados com brometo de etídeo.

\subsubsection{Amplificação da região LCR}

Para a amplificação da região LCR foram utilizadas biópsias de 30 pacientes positivos para HPV-6. A região LCR completa, incluindo o promotor P90 (posições de 7292 até 101 do genoma) de HPV-6 foi amplificada utilizando-se os oligonucleotideos iniciadores específicos HPV6-LCR-F (TTAAGCGCCCTGCTGTTTCCAAAG) e HPV6-LCR-R (TCTCTGCTGTGGTCAGTGCATTCT). A reação consistiu de um mix de $1 U$ de High Fidelity DNA Polymerase Enzyme (Fermentas), $5 \mu \mathrm{l}$ de High Fidelity PCR Buffer (10X), $1.5 \mathrm{mM}$ de $\mathrm{MgCl}_{2}, 0.25 \mathrm{mM}$ de cada dNTPs (Invitrogen), 40 pmoles de cada oligonucleotídeo iniciador e 500 ng de DNA purificado, com volume final de $50 \mu \mathrm{L}$. As reações deram-se nas seguintes condições: após o passo inicial de desnaturação a $95^{\circ} \mathrm{C}$ por $5 \mathrm{~min}$, foram realizados 40 ciclos de $95^{\circ} \mathrm{C}$ por $1 \mathrm{~min}$, $55^{\circ} \mathrm{C}$ por 1 min e $72^{\circ} \mathrm{C}$ por 2 min, seguidos de uma fase final de extensão de $72^{\circ} \mathrm{C}$ por $8 \mathrm{~min}$. Duas amplificações independentes foram realizadas para cada amostra para se evitarem possíveis erros inerentes à polimerase.

\subsubsection{Clonagem}

Inicialmente, os produtos de PCR foram purificados por precipitação com etanol. Em um tubo de 1,5 mL, foram misturados $45,0 \mu \mathrm{L}$ de produto da reação de $\mathrm{PCR}, 2,7 \mu \mathrm{L}$ de acetato de sódio $3 \mathrm{M}$ e $135,0 \mu \mathrm{L}$ de etanol gelado absoluto. Após incubação overnight a $-80^{\circ} \mathrm{C}$, os tubos foram centrifugados a $13200 \mathrm{rpm}$, por 20 min a $4^{\circ} \mathrm{C}$. O sobrenadante foi descartado por inversão e foram adicionados ao pellet $100 \mu \mathrm{L}$ de etanol $70 \%$ gelado, seguindo-se outra centrifugação a 13200rpm, por 10 min a $4^{\circ} \mathrm{C}$. O sobrenadante foi descartado por inversão e os tubos foram deixados para secar em temperatura ambiente. O pellet foi ressuspendido em 20 $\mu \mathrm{L}$ de $\mathrm{H}_{2} \mathrm{O}$ Milli-Q e a presença do DNA confirmada em gel de agarose $1,5 \%$. Os 
produtos da amplificação das regiões E6 e LCR purificados foram, então, clonados usando TOPO XL PCR Cloning ${ }^{\mathrm{TM}}$ Kit (Thermo Scientific) e PCR XLTOPO Vector (Thermo Scientific), respectivamente. Cinco clones de cada paciente foram purificados utilizando o GeneJET Plasmid Purification Kit (Thermo Scientific).

\subsubsection{Sequenciamento de DNA}

Os fragmentos clonados foram sequenciados utilizando-se BigDye® Terminator v3.1 Cycle Sequencing Kit (Applied Biosystems) e os produtos foram sequenciados no equipamento ABI 3130XL Genetic Analyser (Applied Biosystems). As reações de sequenciamento foram realizadas com os mesmos oligonucleotídeos iniciadores utilizados para a amplificação das amostras. Para a reação de sequenciamento foram misturados 2,0 $\mu \mathrm{L}$ de $5 \mathrm{X}$ Sequencing Buffer (Applied Biosystems), 0,4 mM de cada oligonucleotídeo iniciador, 2,0 $\mu \mathrm{L}$ de BigDye Terminator e 5,0 $\mu \mathrm{L}$ de amostra. A reação foi realizada com um passo inicial de $10 \min$ a $95^{\circ} \mathrm{C}$, seguido de 30 ciclos de $96^{\circ} \mathrm{C}$ por 15 segundos, um ciclo de $50^{\circ} \mathrm{C}$ por 15 segundos e um ciclo de $60^{\circ} \mathrm{C}$ por $4 \mathrm{~min}$. A fim de se controlarem as mutações inerentes à polimerase, dois produtos diferentes de PCR foram clonados e sequenciados.

A qualidade das sequências obtidas nas reações foi analisada pelo programa Eletropherogram Quality Analysis. As comparações entre as sequências obtidas neste estudo e as previamente depositadas no Gen Bank foram realizadas usando-se o programa BLAST (Basic Local Alignment Search Too). O alinhamento dessas sequências protótipos e das amostras em ambas as orientações foi realizado pelo programa CLUSTAL W, incluído no pacote Bioedit 7.0.9.0 (Thompson et al., 1994; Hall, 1999). Todas as sequências foram editadas usando BioEdit (Hall, 1999) para remover fragmentos de vetores de clonagem e analisar somente sequências completas dos genes. As sequências de nucleotídeos de HPV-6 e HPV-11, geradas neste estudo, foram depositadas no Gen Bank (accession numbers: KC285838-KC285862). 


\subsubsection{Análise da estrutura secundária in silico}

As alterações de aminoácidos e estruturas secundárias da proteína E6 das variantes de HPV-6vc e -6nvc foram comparadas com o Predict Protein Server, (Rost et al., 2004).

\subsubsection{Análise filogenética}

A análise filogenética foi realizada utilizando-se a ferramenta PhyML, disponibilizada pela South of France Bioinformatics Platform (Guindon; Gascuel, 2003; Guindon et al., 2010). Árvores filogenéticas de máxima verossimilhança foram construídas utilizando-se o modelo TrN para as sequências de HPV-6 e o modelo HKY85 para as sequências de HPV-11. Os modelos foram determinados utilizando-se o programa Modeltest 3.7 (Posada; Crandall, 1998), que está no pacote PAUP 4.0 beta10 (Swofford, 2002). O bootstrap foi calculado com base em 1000 réplicas, e os valores acima de $70 \%$ foram considerados significativos. Essa análise filogenética incluiu todas as sequências de E6 obtidas neste estudo juntamente com outras sequências completas de E6 encontradas na literatura: 77 isolados de HPV-6 da Eslovênia (Kocjan et al., 2009), 12 isolados de HPV-6 da África do Sul (Combrinck et al., 2012) e 63 isolados de HPV-11 da Eslovênia (Maver et al., 2011), obtidos de diferentes sítios anatômicos como papilomas laríngeos, verrugas genitais, câncer genital e swabs anais.

\subsubsection{Análise estatística}

Os pacientes que apresentaram HPV nas amostras foram, então, divididos em dois grupos: os que com HPV-6 e os com HPV-11. Os com HPV-6 foram ainda subdivididos de acordo com a variante apresentada: devido ao pequeno número de pacientes com variantes $-a$ ou $-b$, estes foram subdividos em apenas dois grupos: HPV 6-vc e HPV 6 não-vc. Esses grupos foram comparados entre si, de acordo com os achados clínicos.

Para a comparação do número absoluto e das médias de cirurgias entre os grupos e subgrupos de pacientes, foi utilizado o modelo de regressão de Poisson. 
Para a avaliação da agressividade da doença, de acordo com o escore de Derkay, este foi ajustado pelo modelo de Regressão Beta Binomial com comparação das médias entre os grupos de interesse. Para a avaliação da presença de traqueostomia foram ajustados modelos de Regressão Log-Binomial para a estimação de riscos relativos.

Em todas as análises, foram ajustados modelos simples, considerando-se apenas os tipos ou as variantes estudadas, e múltiplos, a fim de se controlarem possíveis efeitos da idade sobre os resultados.

Para o ajuste da idade foi considerada como nota de corte a idade de 12 anos no momento da primeira cirurgia, baseada em estudos anteriores, que demonstram que a PRR juvenil apresenta comportamento diferente da PRR adulta (Wiatrak et al., 2004).

Para todas as análises, o software utilizado foi o SAS 9.3. 
5. Resultados 
Foram colhidas amostras de 43 pacientes, sendo que dois foram excluídos pois não foi possível sua genotipagem. Dos 41 restantes, $28(68,29 \%)$ eram do sexo masculino e $13(31,70 \%)$ do sexo feminino. Desses, $26(63,41 \%)$ eram maiores de 12 anos e 15 (36,58\%) menores de 12 anos. Dos 15 menores de 12 anos, sete $(46,66 \%)$ eram do sexo masculino e oito $(53,33 \%)$ do sexo feminino. Já dos 26 maiores de 12 anos, 21 (80,76\%) eram do sexo masculino e cinco $(19,24 \%)$ do sexo feminino. O número médio de cirurgias às quais os pacientes foram submetidos foi maior no grupo com idade menor de 12 anos (7,00 \pm 5,71 cirurgias) do que no grupo com idade maior de 12 anos (3,58 $\pm 2,27$ cirurgias). Essa diferença foi considerada estatisticamente relevante $(p<0,01$; estimativa: $-3,36$; IC 95\%: -5,54;-1,18) (Figura 2).

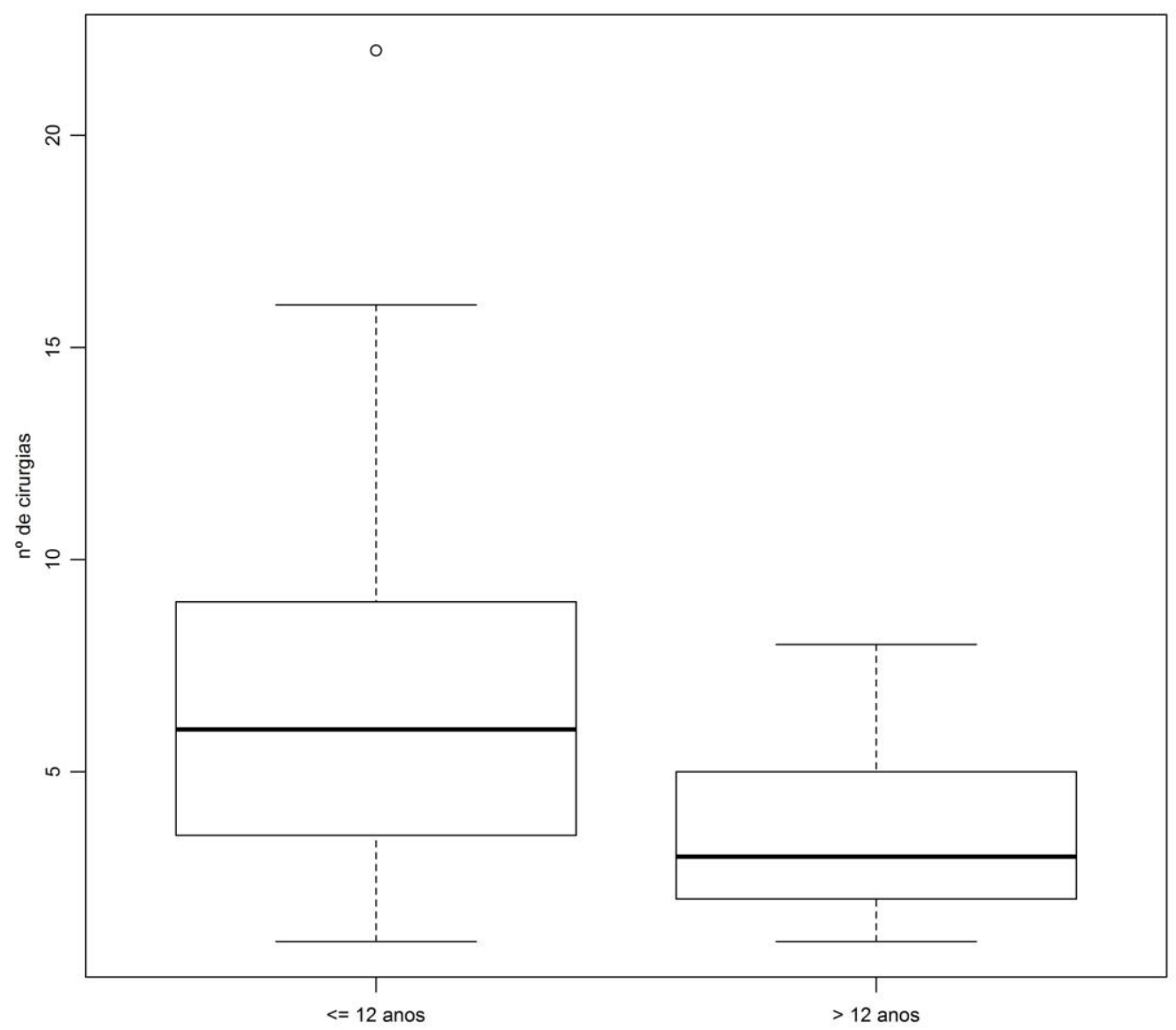

Figura 2: Número de cirurgias vs idade dos pacientes. 
O Derkay médio durante as cirurgias também foi maior no grupo com idade menor de 12 anos $(12,33 \pm 5,65)$ do que no grupo com idade maior de 12 anos $(8,23 \pm 3,55)$. Essa diferença também foi considerada estatisticamente relevante ( $p<0,01$; estimativa: $-3,76$; IC 95\%: -6,35;-1,12) (Figura 3).

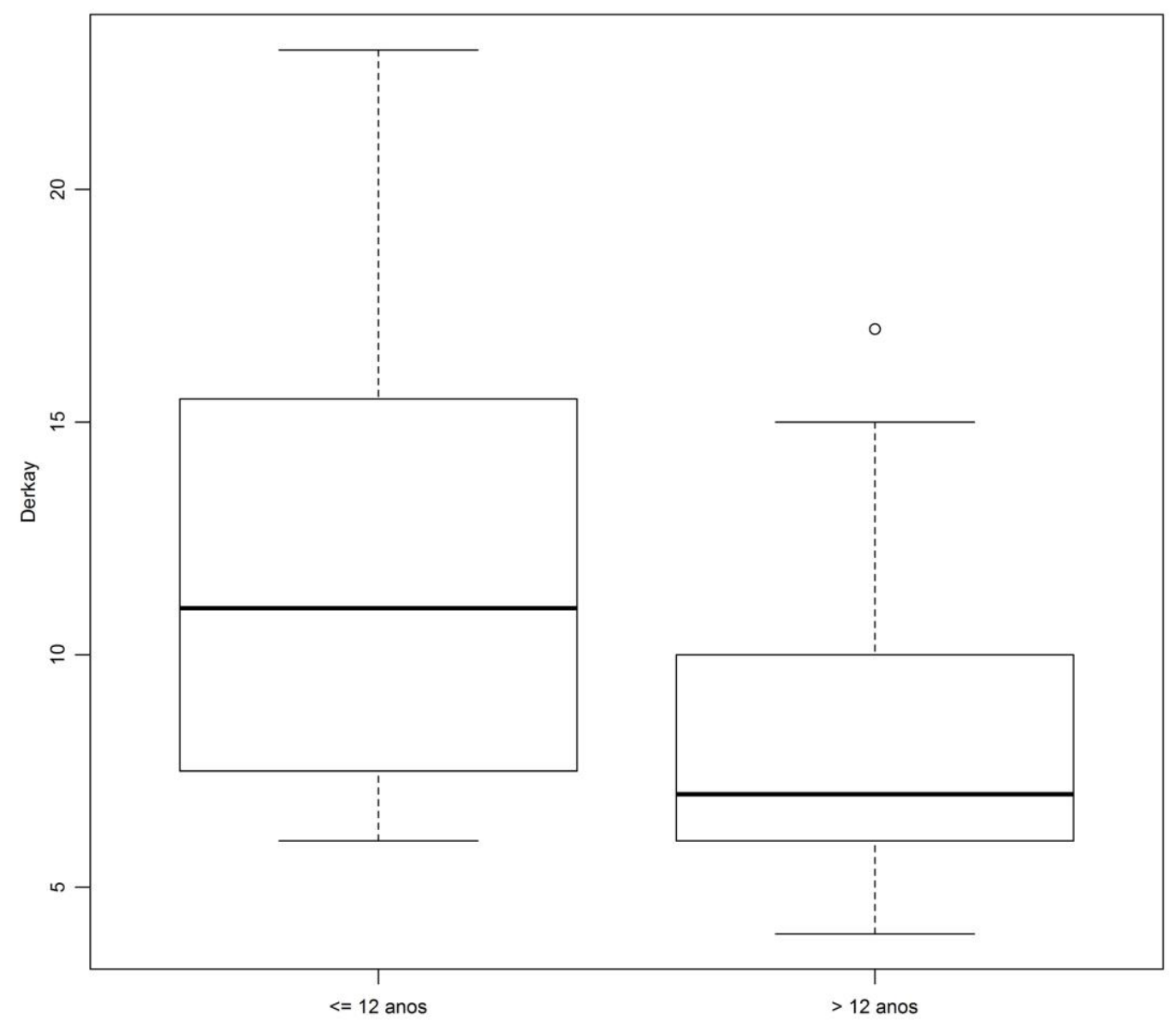

Figura 3: Escore de Derkay vs idade dos pacientes.

A traqueostomia foi necessária em três (20\%) pacientes com idade menor de 12 anos e em dois (7,69\%) maiores de 12 anos. Essa diferença não foi, contudo, considerada significativa $(p=1,00)$. 


\section{Comparação entre tipos de HPV}

O HPV-6 foi identificado em $30(73,17 \%)$ pacientes, enquanto que o HPV11 foi observado em onze (26,83\%). Entre os maiores de 12 anos, o HPV-6 esteve presente em 22 (84,61\%), enquanto que o HPV-11 foi identificado em quatro (15,38\%). Já nos menores de 12 anos, o HPV-6 esteve presente em oito $(53,33 \%)$ e o HPV-11 em sete $(46,66 \%)$.

Em relação ao número de cirurgias, verificou-se que os pacientes HPV-6 foram submetidos, em média, a 4,0 \pm 2,46 cirurgias, enquanto que os HPV-11, em média, a 7,09 \pm 6,66 cirurgias. Essa diferença foi considerada estatisticamente significativa ( $p<0,02$; estimativa: 3,03; IC95\%: 0,47;5,59) (Figura 4).

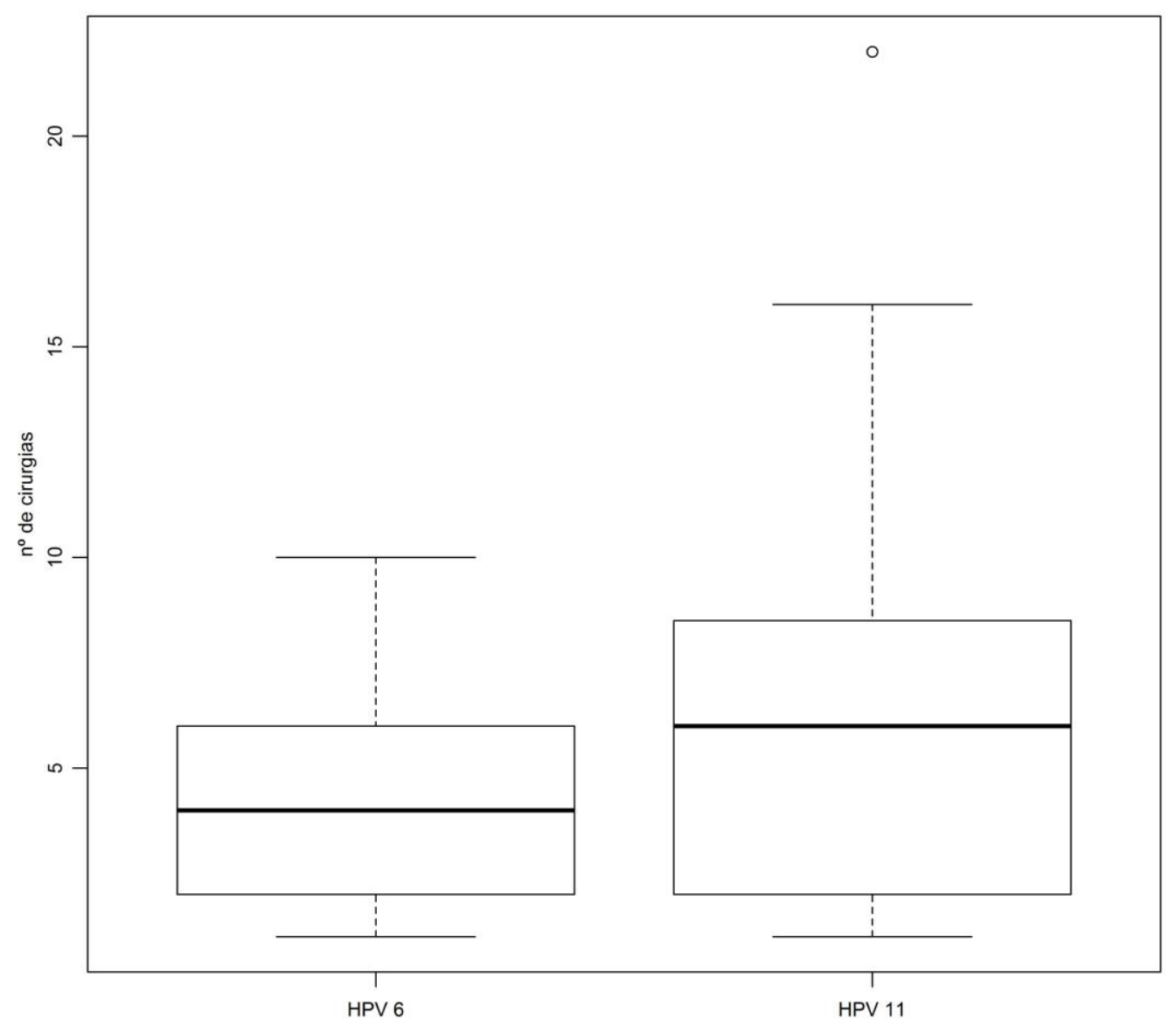

Figura 4: Número de cirurgias vs tipos de HPV. 
No entanto, quando utilizado o modelo estatístico levando em conta a idade como covariante, a diferença estatística perdeu significância ( $p=0,10$; estimativa: 2,54; IC95\%: -0,47;5,55). Nos pacientes menores de 12 anos, os com tipo HPV-6 foram submetidos, em média, a 5,63 $\pm 2,92$ cirurgias e os com tipo HPV-11, em média, a 8,57 $\pm 7,79$. Já nos maiores de 12 anos, os com HPV-6 foram submetidos, em média, a 3,41 $\pm 2,04$ cirurgias, e os com HPV-11 foram operados, em média, 4,50 $\pm 3,51$ vezes.

Em relação ao escore de Derkay, os pacientes com HPV-6 apresentaram escore médio de 8,4 $\pm 3,31$ e os com HPV-11 obtiveram escore médio de 13,36 \pm $6,38$. Essa diferença foi significativa ( $p<0,01$; estimativa: 4,39; IC $95 \%: 2,59 ; 6,19)$ (Figura 5) e se manteve assim nos menores de 12 anos (Derkay médio de 9,25 \pm 2,66 nos pacientes com tipo HPV-6 vs Derkay médio de 15,86 $\pm 6,26$ nos com HPV-11; $p<0,01$; estimativa: 6,15; IC95\%: 4,95;7,36). Já nos maiores de 12 anos, o Derkay médio foi semelhante entre os dois grupos (média de 8,09 $\pm 3,52$ nos com HPV-6 e de 9,00 $\pm 4,16$ nos com HPV-11; $p=0,24$; estimativa: 0,84; IC 95\%; $-0,60 ; 2,30)$. A traqueostomia foi necessária em dois (2,67\%) pacientes HPV-6 e em três $(27,27 \%)$ com HPV-11, não havendo diferença significativa de prevalência entre os dois tipos. 


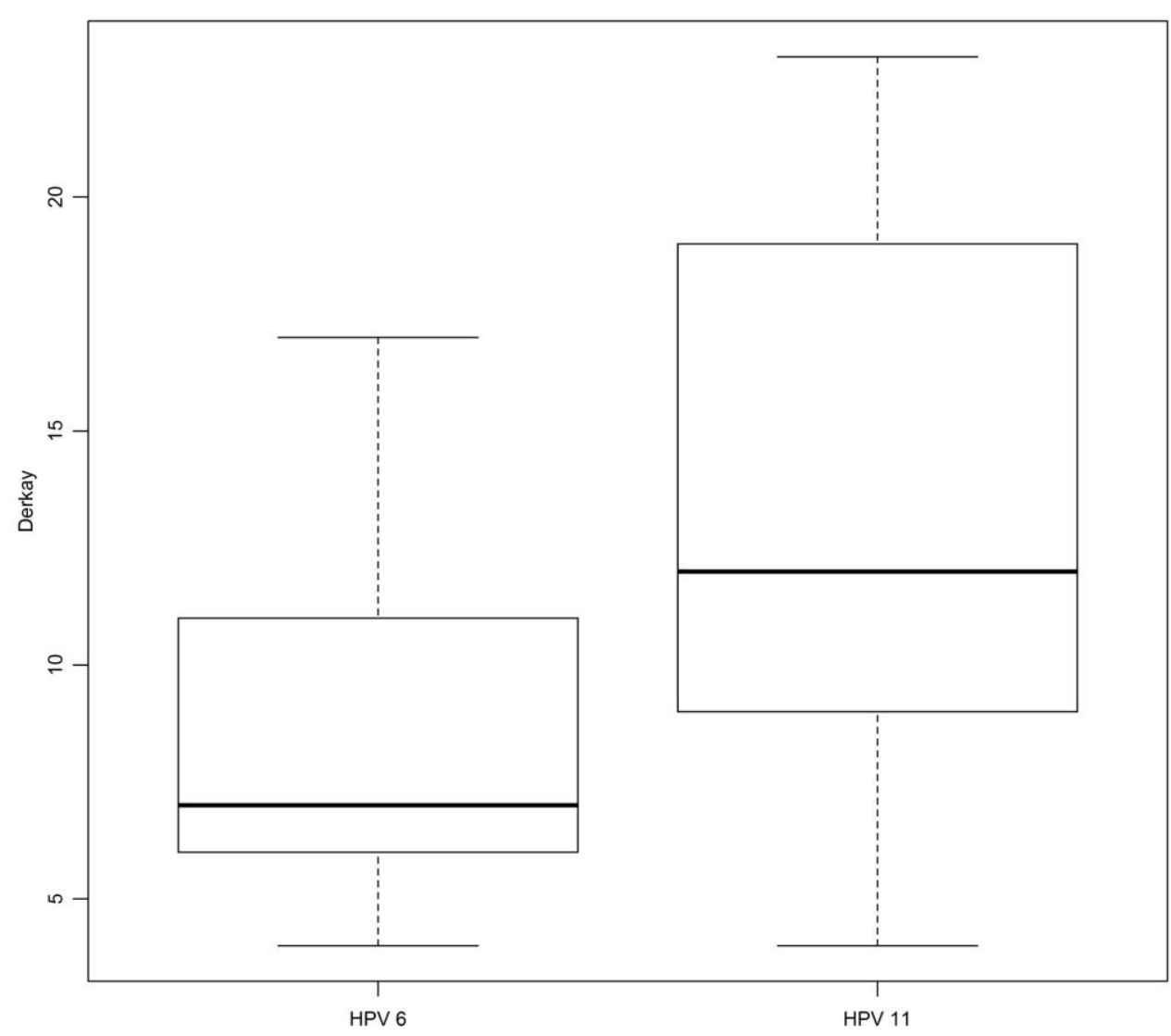

Figura 5: Escore de Derkay vs tipos de HPV.

\section{Comparação entre variantes de HPV- $\underline{6}$}

Entre os 30 pacientes com HPV-6, 27 foram amplificados e identitificados: a forma HPV6-vc foi identificada em 17 (62,96\%), sendo que seis (35,29\%) eram menores e 11 (64,71\%) maiores de 12 anos. Já as formas não variantes (HPV6nvc) foram observadas em 10 (37,03\%) pacientes, sendo que um (10\%) paciente era menor de 12 anos e nove (90\%) pacientes maiores de 12 anos. Os com HPV6-vc realizaram, em média, 3,71 $\pm 2,93$ cirugias, enquanto que os com HPV6nvc, em média, 4,50 $\pm 1,78$ cirurgias. Essa diferença não foi considerada significativa ( $p=0,42$; estimativa: $-0,79$; IC 95\%: -2,70;1,13) (Figura 6). 


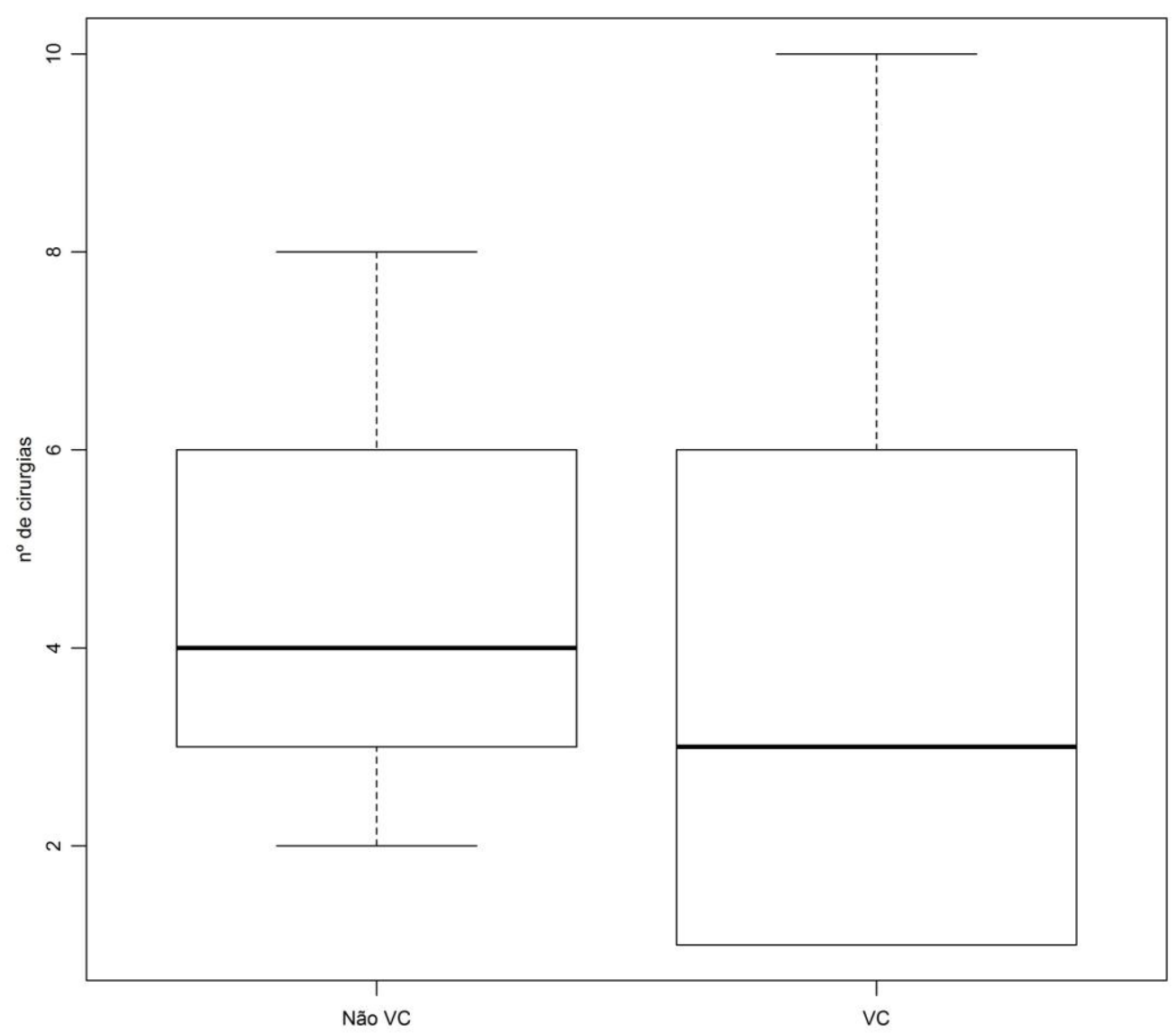

Figura 6: Número de cirurgias vs HPV-6, variante e não variante.

No modelo estatístico em que se considerou a idade como covariante, a diferença se manteve não significativa ( $p=0,14$; estimativa: $-2,51$; IC95\%: $-5,82 ; 0,80)$. Nos pacientes menores de 12 anos, os com HPV6-vc foram submetidos, em média, a 5,83 $\pm 3,43$ cirurgias e os com HPV-6nvc, em média, a $5,00 \pm 0,00$ cirurgias. Já nos maiores de 12 anos, os com HPV6-vc foram submetidos, em média, a 2,55 \pm 1,02 cirurgias, e os com HPV6-nvc foram operados, em média, 4,44 $\pm 1,88$ vezes.

Em relação ao escore de Derkay, os HPV6-vc apresentaram escore médio de 8,18 $\pm 3,34$ e os com HPV6-nvc escore médio de 7,70 $\pm 2,75$, sendo que a diferença não foi considerada estatisticamente relevante $(p=0,96$; estimativa: -0,20; IC 95\%: -7,92;7,59) (Figura 7). Essa diferença se manteve não significativa nos pacientes menores de 12 anos (Derkay médio de 9,00 $\pm 2,45$ nos com HPV6vc vs Derkay médio de 7,00 $\pm 0,00$ no com HPV6-nvc; $p=0,41$; estimativa: 2,08; 
IC 95\%: -3,06;7,24), assim como nos maiores de 12 anos, (média de 7,73 \pm 3,77 nos com HPV6-vc vs média de 7,78 \pm 2,91 nos com HPV6-nvc; $p=0,99$; estimativa: 0,00; IC 95\%; -3,22;3,23).

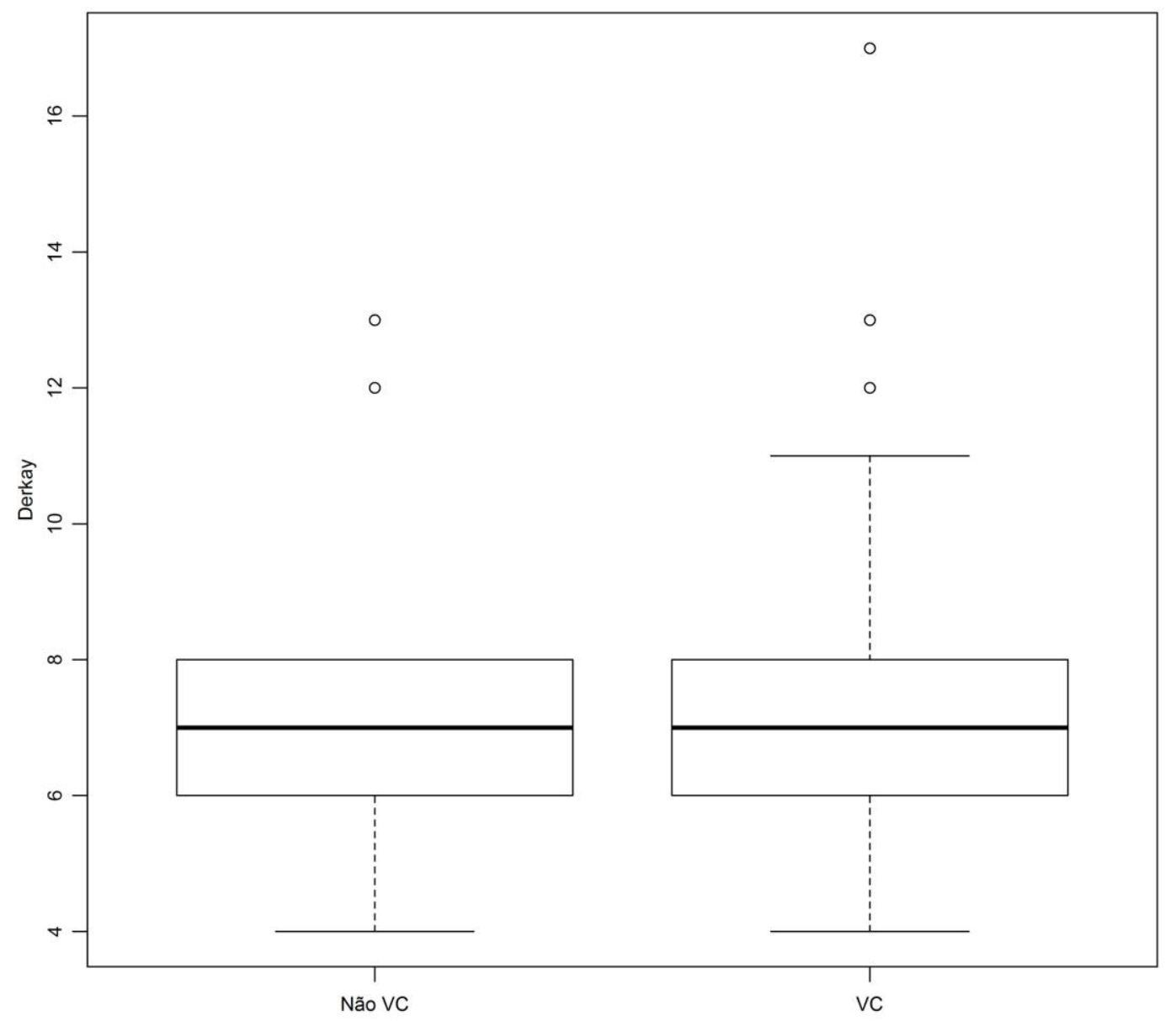

Figura 7: Escore de Derkay vs tipo de HPV-6, variante e não variante. 
6. Discussão 
A papilomatose laríngea ainda é, nos dias atuais, uma das doenças mais desafiadoras enfrentadas pela comunidade médica. Apesar dos inúmeros avanços nos estudos e conhecimentos da fisiopatologia da doença, ela continua sendo um grande desafio médico com terapias, muitas vezes, frustrantes, tanto para os médicos como para os pacientes. Apesar do seu caráter benigno em relação à agressividade tumoral, sua manifestação clínica costuma ser bastante exuberante interferindo muito na qualidade de vida do paciente; podendo, em casos mais graves, levar à morte (Carifi et al., 2015).

Neste estudo, procurou-se identificar os tipos de HPV e suas variantes, e relacioná-los com a agressividade da doença. A maioria dos pacientes era de adultos e o sexo predominante, em geral, foi o masculino. Esse predomínio do sexo masculino deveu-se, sobretudo, ao grupo acima de 12 anos, em que $80 \%$ dos pacientes eram homens. Já entre os menores de 12 anos, houve equilíbrio de gêneros, com $46 \%$ do sexo masculino e $54 \%$ do sexo feminino. Essa diferença de distribuição entre gêneros nas diferentes idades já foi relatada em literatura, com equivalência entre os gêneros nas crianças (Lindeberg; Elbrønd, 1990; Armstrong et al., 2000; Campisi et al., 2010), enquanto que nos adultos houve franco predomínio em pacientes masculinos (Tjon Pian Gi et al., 2015). Entretanto, Omland et al. (2012), em um estudo populacional com 115 pacientes com PRR, identificaram prevalência maior do sexo masculino em pacientes menores de 12 anos de idade, diferente do que havia sido descrito anteriormente na literatura.

Os pacientes com idade inferior a 12 anos necessitaram de número médio significativamente maior de cirurgias para o controle da doença, bem como apresentaram escore de Derkay médio também significativamente maior. No entanto, o número de pacientes que necessitaram de traqueostomia no decorrer do tratamento foi semelhante entre os grupos. Este achado pode ser explicado pelo pequeno número de pacientes que necessitaram de traqueostomia. Os resultados em conjunto evidenciam maior agressividade da doença em crianças mais jovens. Estes dados estão de acordo com outros estudos da literatura. Buchisnk et al. (2008) avaliaram 118 crianças com PRR analisando o tipo de vírus e a agressividade da doença (mensurada pelo número total e pela 
frequência de cirurgias, pelo envolvimento extralaríngeo da doença e pela necessidade de traqueostomia). Os autores concluíram que a idade foi mais importante do que o tipo de vírus como fator de risco na clínica da PRR.

Tjon Pian Gi et al. (2015) analisaram 58 pacientes com PRR, relacionando tipo viral e agressividade. Neste estudo, a agressividade foi mensurada pelo escore de Derkay, pela presença de doença extralaríngea e pelo número de cirurgias. De novo, a idade precoce de aparecimento da doença foi o fator de risco mais importante para a agressividade da doença.

Omland et al. (2014), em um estudo de coorte, avaliaram também os fatores de risco (gênero, idade de aparecimento da doença, tipo de HPV e tempo de evolução da doença) em 224 pacientes menores e maiores de 18 anos com PRR agressiva. A agressividade da doença foi determinada pela presença de doença extralaríngea, necessidade de traqueostomia, frequência de pelo menos quatro cirurgias ao ano e pelo número maior que 10 cirurgias por paciente. Esse estudo evidenciou a idade de aparecimento da doença como único fator de risco significativo para o desenvolvimento de PRR agressiva.

A relação do HPV com a papilomatose laríngea já foi bem estabelecida (Mounts et al., 1982) e os tipos mais comumente envolvidos foram os HPVs considerados de baixo risco tumoral, do tipo 6 e 11. Nos últimos anos, as variantes do HPV vêm recebendo especial atenção da comunidade científica. Entretanto, até o momento, não existem estudos relacionando as variantes do HPV e suas manifestações clínicas, sobretudo sobre a sua possível relação com a maior gravidade.

No presente estudo, o HPV-6 e o HPV-11 foram identificados, respectivamente, em 30 (73\%) e em 11 (27\%) pacientes. A prevalência exclusiva dos tipos 6 e 11 se assemelha aos dados da literatura que mostram prevalência de 70 a 98\% desses dois tipos de HPV (Peñaloza-Plascencia et al., 2000).

Em relação à distribuição dos tipos de HPV nas faixas etárias, identificouse distribuição equânime dos tipos virais nos pacientes menores de 12 anos e prevalência quase exclusiva de HPV-6 naqueles acima de 12 anos. Estes resultados também foram observados por outros autores (Pou et al., 1995; Gabott et al., 1997; Wiatrak et al., 2004). Entretanto, Padayachee e Prescott (1993) e 
Draganov et al. (2006) encontraram resultados divergentes com prevalência de HPV-11 na população estudada. Na literatura, não há consenso sobre a prevalência de um tipo de vírus em determinada faixa etária e segundo Donne e Clarke (2010), este fato ocorreria em razão da doença ser rara, com poucos estudos epidemiológicos. Xi et al (2006) afirmam, ainda, que a PRR é causada por diferentes tipos de vírus, acometendo populações geograficamente distintas, o que dificulta melhor análise epidemiológica.

Os pacientes HPV-11 apresentaram escore médio de Derkay significativamente maior do que os HPV-6. Houve manutenção dessa diferença entre as crianças menores, sendo que as com HPV-11 mantiveram escores significativamente maiores do que as com HPV-6, mas essa diferença não foi significativa nos pacientes maiores.

Os pacientes com HPV-11 foram submetidos, ainda, em média, a 7,09 cirurgias para controle da doença, enquanto os com HPV-6 necessitaram de somente 4,0 cirurgias, o que sugere comportamento mais recidivante para os portadores de HPV-11 quando comparados aos com HPV-6. No entanto, quando utilizada a idade como cofator nessa análise, essa diferença deixou de ser significativa. Isso demonstra que a suposta pior recidiva nos pacientes HPV-11 está, na verdade, relacionada à menor idade desses pacientes, e não ao tipo de HPV per se.

O estudo de fatores relacionados à agressividade da PRR é controverso na literatura. Enquanto que Wiatrak et al. (2004), Hočevar-Boltežar et al. (2014), latakorn et al.(2014) e Tjon Pian Gi et al. (2015) referem que o HPV-11 está associado à necessidade de maior número de cirurgias e pior escore de Derkay. Gabbot et al. (1997) e Peñaloza-Plascencia et al. (2000) referem alta agressividade do HPV-6, sobretudo na faixa etária adulta. Já Omland et al. (2014), demonstram que o HPV-11 e o acompanhamento clínico por mais de 10 anos se constituíram em fatores de risco para PRR agressiva em pacientes adultos.

No presente estudo, avaliou-se também o comportamento clínico de acordo com as variantes do HPV-6. Dentre os 27 pacientes genotipados como HPV-6, 17 (62,96\%) eram HPV-vc e 10 HPV-nvc. O número de cirurgias 
realizadas nos grupos variantes e não variantes foi semelhante, não havendo diferença significativa entre eles. O mesmo padrão foi observado em relação ao escore de Derkay, em que também não se evidenciou diferença estatística significativa entre os dois grupos. Essas duas variáveis foram, ainda, corrigidas pela idade como cofator, e a similaridade entre os grupos variantes e não variantes foi mantida para as duas faixas etárias analisadas. Não existem estudos que tenham avaliado o comportamento clínico das variantes do HPV-6 e sua possível agressividade, seja na PRR juvenil ou na adulta. Muito se especula sobre a variabilidade genética do HPV e sua repercussão clínica nas diferentes doenças causadas por ele, porém este é o primeiro estudo que avaliou especificamente esta relação. Outros estudos já identificaram as variantes do HPV e as genotipam na PRR, ou até relataram as suas mutações, mas não realizaram a correlação clínica (Cornet et al., 2013; Kcojan et al., 2013).

Não há consenso na literatura sobre a real importância das mutações encontradas nas formas variantes e sua influência na atividade do vírus (integração ao DNA do hospedeiro, replicação, patogenicidade, ou transformação maligna). Uma alteração na região controladora do vírus por si só não significa maior agressividade. Measso do Bonfim et al. (2015) identificaram, pela primeira vez, nas amostras dos pacientes participantes do presente estudo, seis tipos de HPVs variantes com mutações na LCR. Essas mutações causaram alterações na atividade celular, sendo que os HPV-vc foram transcricionalmente mais ativos do que os HPV-nvc, porém essa diferença não se relacionou à maior agressividade do HPV, como observado neste estudo.

A PRR expressa uma relação vírus-hospedeiro complexa e ainda desconhecida. Um dos exemplos dessa complexidade é o número expressivamente maior de pessoas que entram em contato com o HPV do que o das que desenvolvem a doença.

Acredita-se que estudos sobre a imunidade do hospedeiro possam elucidar esta discussão. Diferenças nas respostas imunológicas dos pacientes acometidos por PRR poderiam justificar quadros clínicos tão distintos. Buchinsky et al. (2004) fazem suposições sobre possíveis fatores genéticos de suscetibilidade à infecção pelo HPV. Stern et al. (2007) observaram em pacientes com PRR menor 
concentração sérica de CD4 e CD8 e resposta linfocitária deficiente em relação aos não acometidos pela doença. Dessa forma, alterações na imunidade celular poderiam justificar as inúmeras recidivas nos pacientes com PRR.

Recentemente, Lucs et al. (2015) mostraram que pacientes com PRR apresentam resposta imunológica inata e adquirida ineficaz contra o capsídio viral do HPV, com supressão de linfócitos Th1 e polarização para linfócitos Th2 e Treg, e consequente diminuição de interferon- $\gamma$, interleucina 2 e fator de necrose tumoral, citocinas essenciais para o combate ao vírus. Esse mesmo grupo já havia observado aumento na expressão de ciclooxigenase-2 (COX-2) em tecidos com papilomatose em relação ao tecido normal de pacientes com PRR. Segundo os autores, essa concentração maior de COX -2 levaria à alteração da resposta imune local; constituindo-se, assim, em importante fator de risco para 0 agravamento da doença (Lucs et al., 2012).

Hatam et al. (2012) relataram que pacientes portadoras de PRR apresentavam perfil inflamatório polarizado para Th2 e Treg; no entanto quando as células Treg foram estimuladas em laboratório, elas não foram adequadamente funcionantes, e os autores sugeriram que elas estivessem cronicamente ativadas e exaustas, demonstrando haver mais um mecanismo de imunossupressão nessa população, em específico.

A PRR continua sendo uma doença que necessita de maior esclarecimento sobre a sua fisiopatogenia. Novos estudos sobre os diferentes tipos de HPV, suas formas variantes, e sobretudo sobre a complexa interação entre o HPV e o hospedeiro, são essenciais para o desenvolvimento de futuras terapêuticas mais específicas e eficazes. 
7. Conclusões 
Após análise dos resultados, concluiu-se que:

- Os tipos de HPV-6 e HPV-11, considerados de baixo risco tumoral, foram identificados em $100 \%$ dos pacientes.

- Houve predomínio do tipo 6, principalmente nos pacientes adultos.

- Nas crianças com menos de 12 anos, a distribuição entre o HPV-11 e HPV-6 foi equânime.

- Houve maior extensão da doença e maior número de recidivas nos pacientes com idade menor de 12 anos ao diagnóstico.

- A agressividade da PRR não esteve relacionada ao tipo viral (HPV-6 vs HPV-11) e nem às variantes do HPV-6 (vc vs não vc). 


\section{Referências Bibliográficas ${ }^{1}$}

${ }^{11}$ De acordo com a Associação Brasileira de Normas Técnicas. NBR 6023. 
Aaltonen LM, Rihkanen $\mathrm{H}$, Vaheri A. Human papillomavirus in larynx. Laryngoscope. 2002;112(4):700-7.

Abramson AL, Steinberg BM, Winkler B. Laryngeal papillomatosis: clinical, histopathologic and molecular studies. Laryngoscope. 1987;97(6):678-85.

Armstrong LR, Preston EJ, Reichert M, Phillips DL, Nisenbaum R, Todd NW et al. Incidence and prevalence of recurrent respiratory papillomatosis among children in Atlantaand Seattle. Clin Infect Dis. 2000;31(1):107-9.

Avelino MA, Zaiden TC, Gomes RO. Surgical treatment and adjuvant therapies of recurrent respiratory papillomatosis. Braz J Otorhinolaryngol. 2013;79(5):636-42.

Avelino MAG, Pontes PAL. HPV livro: 10. HPV e papiloma de laringe, 2016. Disponível em: http://hpvinfo.com.br/hpv-livro-10-hpv-e-papiloma-de-laringe. Acessado em 21 maio 2016.

Bennett RS, Powell KR. Human papillomaviruses: associations between laryngeal papillomas and genital warts. Pediatr Infect Dis J. 1987;6(3):229-32.

Bercovich JA, Centeno CR, Aguilar OG, Grinstein S, Kahn T. Presence and integration of human papillomavirus type 6 in a tonsillar carcinoma. J Gen Virol. 1991;72(Pt 10):2569-72.

Bernard HU, Chan SY, Manos MM, Ong CK, Villa LL, Delius H et al. Identification and assessment of known and novel human papillomaviruses by polymerase chain reaction amplification, restriction fragment length polymorphisms, nucleotide sequence, and phylogenetic algorithms. J Infect Dis. 1994;170(5):1077-85.

Bernard HU, Burk RD, Chen Z, van Doorslaer K, zurHausen H, de Villiers EM. Classification of papillomaviruses (PVs) based on 189 PV types and proposal of taxonomic amendments. Virology. 2010;401(1):70-9.

Best SR, Friedman AD, Landau-Zemer T, Barbu AM, Burns JA, Freeman MW et al. Safety and dosing of bevacizumab (avastin) for the treatment of recurrent respiratory papillomatosis. Ann Otol Rhinol Laryngol. 2012;121(9):587-93. 
Blackledge FA, Anand VK. Tracheobronchial extension of recurrent respiratory papillomatosis. Ann Otol Rhinol Laryngol. 2000;109(9):812-8.

Brandwein-Gensler M. Laryngeal pathology. In: Water TRVD. (Ed.). Otolaryngology: basic science and clinical review. New York: Thieme Medical Publisher, 2006.

Buchinsky FJ, Derkay CS, Leal SM, Donfack J, Ehrlich GD, Post JC. Multicenter initiative seeking critical genes in respiratory papillomatosis. Laryngoscope. 2004;114(2):349-57.

Buchinsky FJ, Donfack J, Derkay CS, Choi SS, Conley SF, Myer CM 3rd et al. Age of child, more than HPV type, is associated with clinical course in recurrent respiratory papillomatosis. PLoS One. 2008;3(5):e2263.

Campisi P, Hawkes M, Simpson K, Canadian Juvenile Onset Recurrent Respiratory Papillomatosis Working Group. The epidemiology of juvenile onset recurrent respiratory papillomatosis derived from a population level national database. Laryngoscope. 2010;120(6):1233-45.

Carifi M, Napolitano D, Morandi M, Dall'Olio D. Recurrent respiratory papillomatosis: current and future perspectives. Ther Clin Risk Manag. 2015;11:731-8.

Cason J, Best JM, Raju KS. Vertical transmission of human papillomaviruses. Am J Obstet Gynecol. 1999;180(3 Pt 1):774-5.

Chadha NK, James A. Adjuvant antiviral therapy for recurrent respiratory papillomatosis. Cochrane Database Syst Rev. 2012;12:CD005053.

Chan PK, Zhang C, Park JS, Smith-McCune KK, Palefsky JM, Giovannelli L et al. Geographical distribution and oncogenic risk association of human papillomavirus type 58 E6 and E7 sequence variations. Int J Cancer. 2013;132(11):2528-36.

Choi YJ, Park JS2. Clinical significance of human papillomavirus genotyping. J Gynecol Oncol. 2016;27(2):e21. 
Chung BJ, Akst LM, Koltai PJ. 3.5-Year follow-up of intralesional cidofovir protocol for pediatric recurrent respiratory papillomatosis. Int $\mathrm{J}$ Pediatr Otorhinolaryngol. 2006;70(11):1911-7.

Collins JE, Jenkins D, McCance DJ. Detection of human papillomavirus DNA sequences by in situ DNA-DNA hybridisation in cervical intraepithelial neoplasia and invasive carcinoma: a retrospective study. J Clin Pathol. 1988;41(3):289-95.

Combrinck CE, Seedat RY, Randall C, Roodt Y, Burt FJ. Novel HPV-6 variants of human papillomavirus causing recurrent respiratory papillomatosis in southern Africa. Epidemiol Infect. 2012;140(6):1095-101.

Cook JR, Hill DA, Humphrey PA, Pfeifer JD, El-Mofty SK. Squamous cell carcinoma arising in recurrent respiratory papillomatosis with pulmonary involvement: emerging common pattern of clinical features and human papillomavirus serotype association. Mod Pathol. 2000;13(8):914-8.

Cornet I, Gheit T, Clifford GM, Combes JD, Dalstein V, Franceschi S et al. Human papillomavirus type $16 \mathrm{E} 6$ variants in France and risk of viral persistence. Infect Agent Cancer. 2013;8(1):4.

Dartmann K, Schwarz E, Gissmann L, zur Hausen H. The nucleotide sequence and genome organization of human papilloma virus type 11. Virology. 1986;151(1):124-30.

de Araujo Souza PS, Sichero L, Maciag PC. HPV variants and HLA polymorphisms: the role of variability on the risk of cervical cancer. Future Oncol. 2009;5(3):359-70.

de Villiers EM, Gissmann L, zur Hausen H. Molecular-cloning of viral-DNA from human genital warts. J Virol. 1981;40(3):932-5.

de Villiers EM. Papillomavirus and HPV typing. Clin Dermatol. 1997;15(2):199206.

Derkay CS. Task force on recurrent respiratory papillomas. A preliminary report. Arch Otolaryngol Head Neck Surg. 1995;121(12):1386-91. 
Derkay CS. Recurrent respiratory papillomatosis. Laryngoscope. 2001;111(1):5769.

Derkay CS, Hester RP, Burke B, Carron J, Lawson L. Analysis of a staging assessment system for prediction of surgical interval in recurrent respiratory papillomatosis. Int J Pediatr Otorhinolaryngol. 2004;68(12):1493-8.

Derkay CS, Wiatrak B. Recurrent respiratory papillomatosis: a review. Laryngoscope. 2008;118(7):1236-47.

Derkay CS, Volsky PG, Rosen CA, Pransky SM, McMurray JS, Chadha NK et al. Current use of intralesional cidofovir for recurrent respiratory papillomatosis. Laryngoscope. 2013;123(3):705-12.

Dickens P, Srivastava G, Loke SL, Larkin S. Human papillomavirus 6, 11, and 16 in laryngeal papillomas. J Pathol. 1991;165(3):243-6.

Dikkers FG. Treatment of recurrent respiratory papillomatosis with microsurgery in combination with intralesional cidofovir--a prospective study. Eur Arch Otorhinolaryngol. 2006;263(5):440-3.

DiLorenzo TP, Tamsen A, Abramson AL, Steinberg BM. Human papillomavirus type 6a DNA in the lung carcinoma of a patient with recurrent laryngeal papillomatosis is characterized by a partial duplication. J Gen Virol. 1992;73(Pt 2):423-8.

Donne AJ, Rothera MP, Homer JJ. Scientific and clinical aspects of the use of cidofovir in recurrent respiratory papillomatosis. Int J Pediatr Otorhinolaryngol. 2008;72(7):939-44.

Donne AJ, Clarke R. Recurrent respiratory papillomatosis: an uncommon but potentially devastating effect of human papillomavirus in children. Int J STD AIDS. 2010;21(6):381-5.

Donne AJ, Hampson L, Homer JJ, Hampson IN. The role of HPV type in Recurrent Respiratory Papillomatosis. Int J Pediatr Otorhinolaryngol. 2010;74(1):7-14. 
Doorbar J, Ely S, Sterling J, McLean C, Crawford L. Specific interaction between HPV-16 E1-E4 and cytokeratins results in collapse of the epithelial cell intermediate filament network. Nature. 1991;352(6338):824-7.

Draganov P, Todorov S, Todorov I, Karchev T, Kalvatchev Z. Identification of HPV DNA in patients with juvenile-onset recurrent respiratory papillomatosis using SYBR® Green real-time PCR. Int J Pediatr Otorhinolaryngol. 2006;70(3):469-73.

D'Souza G, Kreimer AR, Viscidi R, Pawlita M, Fakhry C, Koch WM et al. Casecontrol study of human papillomavirus and oropharyngeal cancer. $\mathrm{N}$ Engl $\mathrm{J}$ Med. 2007;356(19):1944-56.

El-Bitar MA, Zalzal GH. Powered instrumentation in the treatment of recurrent respiratory papillomatosis: an alternative to the carbon dioxide laser. Arch Otolaryngol Head Neck Surg. 2002;128(4):425-8.

Fehrmann F, Laimins LA. Human papillomaviruses: targeting differentiating epithelial cells for malignant transformation. Oncogene. 2003;22(33):5201-7.

Förster G, Boltze C, Seidel J, Pawlita M, Müller A. Juvenile laryngeal papillomatosis--immunisation with the polyvalent vaccine gardasil. Laryngorhinootologie. 2008;87(11):796-9.

Fusconi M, Grasso M, Greco A, Gallo A, Campo F, Remacle M et al. Recurrent respiratory papillomatosis by HPV: review of the literature and update on the use of cidofovir. Acta Otorhinolaryngol Ital. 2014;34(6):375-81.

Gabbott M, Cossart YE, Kan A, Konopka M, Chan R, Rose BR. Human papillomavirus and host variables as predictors of clinical course in patients with juvenile-onset recurrent respiratory papillomatosis. $\mathrm{J}$ Clin Microbiol. 1997;35(12):3098-103.

Gallagher TQ, Derkay CS. Pharmacotherapy of recurrent respiratory papillomatosis: an expert opinion. Expert Opin Pharmacother. 2009;10(4):645-55.

Gélinas JF, Manoukian J, Côté A. Lung involvement in juvenile onset recurrent respiratory papillomatosis: a systematic review of the literature. Int $\mathrm{J}$ Pediatr Otorhinolaryngol. 2008;72(4):433-52. 
Gissmann L, zur Hausen $\mathrm{H}$. Partial characterization of viral-DNA from human genital warts (condylomata-acuminata). Int J Cancer. 1980;25(5):605-9.

Gissmann L, Diehl V, Schultz-Coulon HJ, zur Hausen H. Molecular cloning and characterization of human papilloma virus DNA derived from a laryngeal papilloma. J Virol. 1982;44(1):393-400.

Goon P, Sonnex C, Jani P, Stanley M, Sudhoff H. Recurrent respiratory papillomatosis: an overview of current thinking and treatment. Eur Arch Otorhinolaryngol. 2008;265(2):147-51.

Gravitt PE, Peyton CL, Alessi TQ, Wheeler CM, Coutlée F, Hildesheim A et al. Improved amplification of genital human papillomaviruses. J Clin Microbiol. 2000;38(1):357-61.

Guindon S, Gascuel O. A simple, fast, and accurate algorithm to estimate large phylogenies by maximum likelihood. Syst Biol. 2003;52(5):696-704.

Guindon S, Dufayard JF, Lefort V, Anisimova M, Hordijk W, Gascuel O. New algorithms and methods to estimate maximum-likelihood phylogenies: assessing the performance of PhyML 3.0. Syst Biol. 2010;59(3):307-21.

Hall TA. BioEdit: a user-friendly biological sequence alignment editor and analysis program for Windows 95/98/NT. Nucl Acids Symp Ser. 1999;41:95-8.

Hatam LJ, Devoti JA, Rosenthal DW, Lam F, Abramson AL, Steinberg BM et al. Immune suppression in premalignant respiratory papillomas: enriched functional CD4+Foxp3+ regulatory T cells and PD-1/PD-L1/L2 expression. Clin Cancer Res. 2012;18(7):1925-35.

Heinzel PA, Chan SY, Ho L, O'Connor M, Balaram P, Campo MS et al. Variation of human papillomavirus type 6 (HPV-6) and HPV-11 genomes sampled throughout the world. J Clin Microbiol. 1995;33(7):1746-54.

Hermann JS, Weckx LY, Monteiro Nürmberger J, Santos Junior GF, Campos Pignatari AC, Nagata Pignatari SS. Effectiveness of the human papillomavirus (types 6, 11, 16, and 18) vaccine in the treatment of children with recurrent respiratory papillomatosis. Int J Pediatr Otorhinolaryngol. 2016;83:94-8. 
Hočevar-Boltežar I, Matičič M, Sereg-Bahar M, Gale N, Poljak M, Kocjan B et al. Human papilloma virus vaccination in patients with an aggressive course of recurrent respiratory papillomatosis. Eur Arch Otorhinolaryngol. $2014 ; 271(12): 3255-62$.

Howley PM, Schiller JT, Lowy DR. Papillomaviruses. In: Knipe DM, Howley PM (Eds.). Fields Virology. 6th Ed. Philadelphia, PA: Kluwer Health/Lippincott Williams \& Wilkins, 2013, cap. 62, p. 2299-354.

larc Monographs on the Evaluation of Carcinogenic Risks to Humans. Lyon, France: World Health Organization, International Agency for Research on Cancer, 2007, 670p.

Intakorn P, Sonsuwan N. Human papillomatosis genotyping and severity in patients with recurrent respiratory papillomatosis. $\mathrm{J}$ Med Assoc Thai. 2014;97(Suppl 6):S136-41.

Kashima HK, Shah F, Lyles A, Glackin R, Muhammad N, Turner L et al. A comparison of risk factors in juvenile-onset and adult-onset recurrent respiratory papillomatosis. Laryngoscope. 1992;102(1):9-13.

Kellokoski J, Syrjänen S, Kataja V, Yliskoski M, Syrjänen K. Acetowhite staining and its significance in diagnosis of oral mucosal lesions in women with genital HPV infections. J Oral Pathol Med. 1990;19(6):278-83.

Kimberlin DW. Current status of antiviral therapy for juvenile-onset recurrent respiratory papillomatosis. Antiviral Res. 2004;63(3):141-51.

King M, Kumar P, Michel D, Batta R, Foldvari M. In vivo sustained dermal delivery and pharmacokinetics of interferon alpha in biphasic vesicles after topical application. Eur J Pharm Biopharm. 2013;84(3):532-9.

Kocjan BJ, Poljak M, Cimerman M, Gale N, Potocnik M, Bogovac Z et al. Prevaccination genomic diversity of human papillomavirus genotype 6 (HPV 6). Virology. 2009;391(2):274-83.

Kocjan BJ, Gale N, HočevarBoltežar I, Seme K, FujsKomloš K, Hošnjak L et al. Identical human papillomavirus (HPV) genomic variants persist in recurrent respiratory papillomatosis for up to 22 years. J Infect Dis. 2013;207(4):583-7. 
Kovelman R, Bilter GK, Roman A, Brown DR, Barbosa MS. Human papillomavirus type 6: classification of clinical isolates and functional analysis of E2 proteins. J Gen Virol. 1999;80 ( Pt 9):2445-51.

Larson DA, Derkay CS. Epidemiology of recurrent respiratory papillomatosis. APMIS. 2010;118(6-7):450-4.

Lee JH, Smith RJ. Recurrent respiratory papillomatosis: pathogenesis to treatment. Curr Opin Otolaryngol Head Neck Surg. 2005;13(6):354-9.

Leventhal BG, Kashima HK, Weck PW, Mounts P, Whisnant JK, Clark KL et al. Randomized surgical adjuvant trial of interferon alfa-n1 in recurrent papillomatosis. Arch Otolaryngol Head Neck Surg. 1988;114(10):1163-9.

Lin HW, Richmon JD, Emerick KS, de Venecia RK, Zeitels SM, Faquin WC et al. Malignant transformation of a highly aggressive human papillomavirus type 11associated recurrent respiratory papillomatosis. Am J Otolaryngol. 2010;31(4):291 6.

Lindeberg $\mathrm{H}$, Elbrønd $\mathrm{O}$. Laryngeal papillomas: the epidemiology in a Danish subpopulation 1965-1984. Clin Otolaryngol Allied Sci. 1990;15(2):125-31.

Lucs AV, Wu R, Mullooly V, Abramson AL, Steinberg BM. Constitutive overexpression of the oncogene Rac1 in the airway of recurrent respiratory papillomatosis patients is a targetable host-susceptibility factor. Mol Med. 2012;18:244-9.

Lucs AV, DeVoti JA, Hatam L, Afzal A, Abramson AL, Steinberg BM et al. Immune Dysregulation in Patients Persistently Infected with Human Papillomaviruses 6 and 11. J Clin Med. 2015;4(3):375-88.

Maver PJ, Kocjan BJ, Seme K, Potočnik M, Gale N, Poljak M. Prevaccination genomic diversity of human papillomavirus genotype 11: a study on 63 clinical isolates and 10 full-length genome sequences. J Med Virol. 2011;83(3):461-70.

McMurray HR, Nguyen D, Westbrook TF, McAnce DJ. Biology of human papillomaviruses. Int J Exp Pathol. 2001;82(1):15-33. 
Measso do Bonfim C, Simão Sobrinho J, Lacerda Nogueira R, Salgado Kupper D, Cardoso Pereira Valera F, Lacerda Nogueira $M$ et al. Differences in Transcriptional Activity of Human Papillomavirus Type 6 Molecular Variants in Recurrent Respiratory Papillomatosis. PLoS One. 2015;10(7):e0132325.

Minkoff $\mathrm{H}$, Chervenak FA. Elective primary cesarean delivery. $\mathrm{N}$ Engl $\mathrm{J}$ Med. 2003;348(10):946-50.

Mohr M, Schliemann C, Biermann C, Schmidt LH, Kessler T, Schmidt J et al. Rapid response to systemic bevacizumab therapy in recurrent respiratory papillomatosis. Oncol Lett. 2014;8(5):1912-8.

Mounts $\mathrm{P}$, Shah KV, Kashima $\mathrm{H}$. Viral etiology of juvenile- and adult-onset squamous papilloma of the larynx. Proc Natl Acad Sci U S A. 1982;79(17):5425-9.

Mounts $\mathrm{P}$, Kashima $\mathrm{H}$. Association of human papillomavirus subtype and clinical course in respiratory papillomatosis. Laryngoscope. 1984;94(1):28-33.

Mudry P, Vavrina M, Mazanek P, Machalova M, Litzman J, Sterba J. Recurrent laryngeal papillomatosis: successful treatment with human papillomavirus vaccination. Arch Dis Child. 2011;96(5):476-7.

Muenscher A, Feucht $\mathrm{HH}$, Kutta $\mathrm{H}$, Tesche $\mathrm{S}$, Wenzel S. Integration of human papilloma virus type 26 in laryngeal cancer of a child. Auris Nasus Larynx. 2009;36(2):232-4.

Muñoz N. Human papillomavirus and cancer: the epidemiological evidence. J Clin Virol. 2000;19(1-2):1-5.

Naiman AN, Ayari S, Nicollas R, Landry G, Colombeau B, Froehlich P. Intermediate-term and long-term results after treatment by cidofovir and excision in juvenile laryngeal papillomatosis. Ann Otol Rhinol Laryngol. 2006;115(9):667-72.

Nikolopoulos TP. HPV and recurrent respiratory papillomatosis: a modern virus and a serious disease with controversial management. Int $J$ PediatrOtorhinolaryngol. 2013;77(12):1917-8. 
Niyibizi J, Rodier C, Wassef M, Trottier H. Risk factors for the development and severity of juvenile-onset recurrent respiratory papillomatosis: a systematic review. Int J Pediatr Otorhinolaryngol. 2014;78(2):186-97.

Omland T, Akre H, Vardal M, Brøndbo K. Epidemiological aspects of recurrent respiratory papillomatosis: a population-based study. Laryngoscope. 2012;122(7):1595-9.

Omland T, Akre H, Lie KA, Jebsen P, Sandvik L, Brøndbo K. Risk factors for aggressive recurrent respiratory papillomatosis in adults and juveniles. PLoS One. 2014;9(11):e113584.

Padayachee A, Prescott CA. Relationship between the clinical course and HPV typing of recurrent laryngeal papillomatosis. The Red Cross War Memorial Children's Hospital experience 1982-1988. Int J Pediatr Otorhinolaryngol. 1993;26(2):141-7.

Pasquale K, Wiatrak B, Woolley A, Lewis L. Microdebrider versus CO2 laser removal of recurrent respiratory papillomas: a prospective analysis. Laryngoscope. 2003;113(1):139-43.

Patel N, Rowe M, Tunkel D. Treatment of recurrent respiratory papillomatosis in children with the microdebrider. Ann Otol Rhinol Laryngol. 2003;112(1):7-10.

Peñaloza-Plascencia M, Montoya-Fuentes H, Flores-Martínez SE, Fierro-Velasco FJ, Peñaloza-González JM, Sánchez-Corona J. Molecular identification of 7 human papillomavirus types in recurrent respiratory papillomatosis. Arch Otolaryngol Head Neck Surg. 2000;126(9):1119-23.

Pereira SMM, Utagawa ML, Maeda MYS, Pittoli JE, Aguiar LS, Longatto Filho A. Implantação do teste de captura de híbridos no Instituto Adolfo Lutz. Bol Inst Adolfo Lutz. 2003;13:4-4.

Pontes P, Avelino M, Pignatari S, Weckx LL. Effect of local application of cidofovir on the control of recurrences in recurrent laryngeal papillomatosis. Otolaryngol Head Neck Surg. 2006;135(1):22-7.

Posada D, Crandall KA. MODELTEST: testing the model of DNA substitution. Bioinformatics. 1998;14(9):817-8. 
Pou AM, Rimell FL, Jordan JA, Shoemaker DL, Johnson JT, Barua P et al. Adult respiratory papillomatosis: human papillomavirus type and viral coinfections as predictors of prognosis. Ann Otol Rhinol Laryngol. 1995;104(10 Pt 1):758-62.

Pransky SM, Brewster DF, Magit AE, Kearns DB. Clinical update on 10 children treated with intralesional cidofovir injections for severe recurrent respiratory papillomatosis. Arch Otolaryngol Head Neck Surg. 2000;126(10):1239-43.

Prince JS, Duhamel DR, Levin DL, Harrell JH, Friedman PJ. Nonneoplastic lesions of the tracheobronchial wall: radiologic findings with bronchoscopic correlation. Radiographics. 2002;22 Spec No:S215-30.

Pudszuhn A, Welzel C, Bloching M, Neumann K. Intralesional Cidofovir application in recurrent laryngeal papillomatosis. Eur Arch Otorhinolaryngol. 2007;264(1):6370.

Puranen MH, Yliskoski MH, Saarikoski SV, Syrjänen KJ, Syrjänen SM. Exposure of an infant to cervical human papillomavirus infection of the mother is common. Am J Obstet Gynecol. 1997;176(5):1039-45.

Rabah R, Lancaster WD, Thomas R, Gregoire L. Human papillomavirus-11associated recurrent respiratory papillomatosis is more aggressive than human papillomavirus-6-associated disease. Pediatr Dev Pathol. 2001;4(1):68-72.

Rad $\mathrm{MH}$, Alizadeh E, Ilkhanizadeh B. Recurrent laryngeal papillomatosis with bronchopulmonary spread in a 70-year-old man. Tuberk Toraks. 2007;55(3):299302.

Ramet J, van Esso D, Meszner Z; European Academy of Paediatrics Scientific Working Group on Vaccination. Position paper--HPV and the primary prevention of cancer; improving vaccine uptake by paediatricians. Eur $\mathrm{J}$ Pediatr. 2011;170(3):309-21.

Reeves WC, Ruparelia SS, Swanson KI, Derkay CS, Marcus A, Unger ER. National registry for juvenile-onset recurrent respiratory papillomatosis. Arch Otolaryngol Head Neck Surg. 2003;129(9):976-82.

Rice PS, Cason J, Best JM, Banatvala JE. High risk genital papillomavirus infections are spread vertically. Rev Med Virol. 1999;9(1):15-21. 
Rost B, Yachdav G, Liu J. The PredictProtein server. Nucleic Acids Res. 2004;32(Web Server issue):W321-6.

Sand L, Jalouli J, Larsson PA, Hirsch JM. Human papilloma viruses in oral lesions. Anticancer Res. 2000;20(2B):1183-8.

Schoell WM, Janicek MF, Mirhashemi R. Epidemiology and biology of cervical cancer. Semin Surg Oncol. 1999;16(3):203-11.

Shah KV, Stern WF, Shah FK, Bishai D, Kashima HK. Risk factors for juvenile onset recurrent respiratory papillomatosis. Pediatr Infect Dis J. 1998;17(5):372-6.

Sidell DR, Nassar M, Cotton RT, Zeitels SM, de Alarcon A. High-dose sublesional bevacizumab (avastin) for pediatric recurrent respiratory papillomatosis. Ann Otol Rhinol Laryngol. 2014;123(3):214-21.

Silverberg MJ, Thorsen P, Lindeberg H, Grant LA, Shah KV. Condyloma in pregnancy is strongly predictive of juvenile-onset recurrent respiratory papillomatosis. Obstet Gynecol. 2003;101(4):645-52.

Smith EM, Pignatari SS, Gray SD, Haugen TH, Turek LP. Human papillomavirus infection in papillomas and nondiseased respiratory sites of patients with recurrent respiratory papillomatosis using the polymerase chain reaction. Arch Otolaryngol Head Neck Surg. 1993;119(5):554-57.

Smith EM, Summersgill KF, Allen J, Hoffman HT, McCulloch T, Turek LP et al. Human papillomavirus and risk of laryngeal cancer. Ann Otol Rhinol Laryngol. 2000;109(11):1069-76.

Snoeck R, Wellens W, Desloovere C, Van Ranst M, Naesens L, De Clercq E et al. Treatment of severe laryngeal papillomatosis with intralesional injections of cidofovir [(S)-1-(3-hydroxy-2-phosphonylmethoxypropyl)cytosine]. J Med Virol. 1998;54(3):219-25.

Stern Y, Felipovich A, Cotton RT, Segal K. Immunocompetency in children with recurrent respiratory papillomatosis: prospective study. Ann Otol Rhinol Laryngol. 2007;116(3):169-71. 
Swofford DL. Phylogenetic analysis using parsimony ("and other methods). Version 4. Sunderland, MA: Sinauer Associates, 2002.

Terai M; Takagi M. Human Papillomavirus in oral cavity. Oral Med Pathol. $2001 ; 6: 1-12$.

Thompson JD, Higgins DG, Gibson TJ. Clustal W: improving the sensitivity of progressive multiple sequence alignment through sequence weighting, positionspecific gap penalties and weight matrix choice. Nucleic Acids Res. 1994;22(22):4673-80.

Tjon Pian Gi RE, San Giorgi MR, Slagter-Menkema L, van Hemel BM, van der Laan BF, van den Heuvel ER et al. Clinical course of recurrent respiratory papillomatosis: comparison between aggressiveness of human papillomavirus-6 and human papillomavirus-11. Head Neck. 2015;37(11):1625-32.

Tjon Pian Gi RE, San Giorgi MR, Pawlita M, Michel A, van Hemel BM, Schuuring EM et al. Immunological response to quadrivalent HPV vaccine in treatment of recurrent respiratory papillomatosis. Eur Arch Otorhinolaryngol. 2016 May 17. [Epub ahead of print].

Ullmann EV. On the aetiology of laryngeal papilloma, Acta Otolaryngol. 1923;5:317-74.

Velyvyte D, Laiskonis A, Uloza V, Gozdzicka-Jozefiak A. Prevalence of papillomavirus infection among patients with laryngeal papillomatosis and the effects of some risk factors on the persistence of papillomaviruses in the upper respiratory tract]. Medicina (Kaunas). 2002;38(5):499-504.

Venuti A, Manni V, Morello R, De Marco F, Marzetti F, Marcante ML. Physical state and expression of human papillomavirus in laryngeal carcinoma and surrounding normal mucosa. J Med Virol. 2000;60(4):396-402.

Werness BA, Levine AJ, Howley PM. Association of human papillomavirus types 16 and 18 E6 proteins with p53. Science. 1990;248(4951):76-9.

Wiatrak BJ, Wiatrak DW, Broker TR, Lewis L. Recurrent respiratory papillomatosis: a longitudinal study comparing severity associated with human 
papilloma viral types 6 and 11 and other risk factors in a large pediatric population. Laryngoscope. 2004;114(11 Pt 2 Suppl 104):1-23.

Wilcox LJ, Hull BP, Baldassari CM, Derkay CS.Diagnosis and management of recurrent respiratory papillomatosis. Pediatr Infect Dis J. 2014;33(12):1283-4.

Wilson WR, Hashemiyoon R, Hawrych A. Intralesional cidofovir for recurrent laryngeal papillomas: preliminary report. Ear Nose Throat J. 2000;79(4):236-8, 240.

Winer RL, Lee SK, Hughes JP, Adam DE, Kiviat NB, Koutsky LA. Genital human papillomavirus infection: incidence and risk factors in a cohort of female university students. Am J Epidemiol. 2003;157(3):218-26.

Xi LF, Kiviat NB, Hildesheim A, Galloway DA, Wheeler CM, Ho J et al. Human papillomavirus type 16 and 18 variants: race-related distribution and persistence. $\mathrm{J}$ Natl Cancer Inst. 2006;98(15):1045-52.

Zeitels SM, Barbu AM, Landau-Zemer T, Lopez-Guerra G, Burns JA, Friedman AD et al. Local injection of bevacizumab (Avastin) and angiolytic KTP laser treatment of recurrent respiratory papillomatosis of the vocal folds: a prospective study. Ann Otol Rhinol Laryngol. 2011;120(10):627-34. 
9. Anexos 


\section{ANEXO A}

\section{SCORE DE DERKAY (Adaptado para o português)}

\section{A - ESCORE CLÍNICO}

1. Descreva a voz do paciente hoje normal (0) anormal (1) afônico (2)

2. Descreva o estridor do paciente hoje ausente (0) presente na respiração (1) presente ao repouso (2)

3. Descreva a urgência da cirurgia hoje agendada (0) eletiva (1) urgente (2) emergência (3)

4. Descreva o nível de distúrbio respiratório hoje nenhum (0) leve (1) moderado (2) severo (3) extremo (4)

Escore total para as quatro questões:

\section{B - ESCORE ANATÔMICO}

Para cada local, o escore será:

(0) ausência; (1) lesão superficial; (2) lesão verrucosa; (3) lesão volumosa

\begin{tabular}{lll} 
Laringe & \multicolumn{2}{l}{} \\
\hline Epiglote & superfície lingual & superfície laríngea \\
Prega ariepiglótica & direita & esquerda \\
Pregas vocais falsas & direita & esquerda \\
Pregas vocais verdadeiras & direita & esquerda \\
Aritenóide & direita & \\
Comissura anterior & & \\
Comissura posterior & & \\
Subglote & & Outros \\
Traqueia & & Nariz \\
\hline Terço superior & Palato \\
Terço médio & Faringe \\
Terço inferior & & Esôfago \\
Brônquio direito/esquerdo & & Pulmão \\
Estoma de traqueostomia & & Outros \\
& & \\
& & \\
C - ESCORE TOTAL & & \\
\hline
\end{tabular}




\section{ANEXO B}

\section{COMPROVANTE DE APROVAÇÃO DO COMITÊ DE ÉTICA}

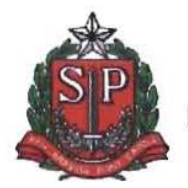

DITAL DAS CLINICAS DA FACULDADE DE MEDICINA DE RIBEIRÃO PRETO DA UNIVERSIDADE DE SĀO PAULO

Oficio $n^{\circ} 402 / 2016$

CEP/MGV
Ribeirāo Preto, 03 de fevereiro de 2016

\section{Prezados Senhores,}

O trabalho intitulado "EsTudo DOS ASPECTOS CLfincos, EPIDEMIOĹ́GICOS E DA VARIABILIDADE GENETICA DE HPV EM PAPILOMATOSE DE LARINGE" - versāo 4, de 16/12/2015, foi analisado pelo Comitê de Ética em Pesquisa em sua $420^{\text {a }}$ Reunião Ordinária, realizada em 01/02/2016 e enquadrado na categoria: APROVADO, bem como o Termo de Consentimento Livre e Esclarecido - versão 3, de 16/12/2015, o Termo de Assentimento - versão 1, de 14/09/2015 e o Biorrepositório, de acordo com o Processo HCRP n ${ }^{\circ} 7735 / 2015$.

De acordo com Carta Circular no $003 / 2011 / C O N E P / C N S$, datada de 21/03/2011, o sujeito de pesquisa ou seu representante, quando for o caso, deverá rubricar todas as folhas do Termo de Consentimento Livre e Esclarecido TCLE - apondo sua assinatura na última do referido Termo; o pesquisador responsável deverá da mesma forma, rubricar todas as folhas do Termo de Consentimento Livre e Esclarecido - TCLE - apondo sua assinatura na última página do referido Termo.

Este Comitê segue integralmente a Conferência Internacional de Harmonização de Boas Práticas Clínicas (IGH-GCP), bem como a Resolução n 466/ 12 CNS/MS

Lembramos que devem ser apresentados a este CEP, o Relatório Parcial e o Relatório Final da pesquisa.

Atenciosamente.

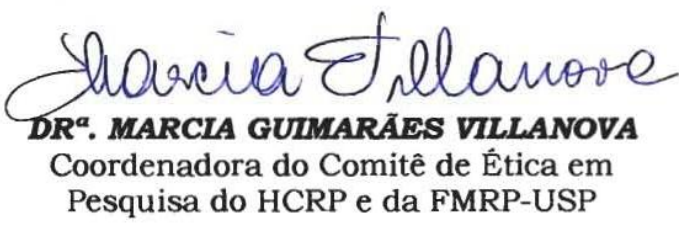

Ilustrissimos Senhores

PROF'.DR ${ }^{\mathrm{a}}$. FABIANA CARDOSO PEREIRA VALERA(OTientadora)

RODRIGO LACERDA NOGUEIRA

Depto. de Oftalmologia, Otorrinolaringologia e Cirurgia de Cabeça e Pescoço

HOSPITAL DAS CLÍNICAS DA FACULDADE DE MEDICINA DE RIBEIRĀO PRETO DA UNIVERSIDADE DE SÃO PAULO Campus Universitário - Monte Alegre 14048-900 Ribeiråo Preto SP 


\section{ANEXO C}

\section{TERMO DE CONSENTIMENTO LIVRE E ESCLARECIDO}

Você foi convidado a participar da pesquisa "Estudo dos aspectos clínicos, epidemiológicos e da variabilidade genética de HPV em papilomatose de laringe", isso porque você possui essa doença. Essa pesquisa quer avaliar os vírus envolvidos nessa doença, e se o tipo deles influencia na agressividade da sua doença.

Para sabermos que você tem a doença, você já fez avaliações, e um exame de laringoscopia, onde um endoscópio observa a região da laringe e vê as lesões típicas da doença. Por causa disso, você foi indicado para a retirada das mesmas com cirurgia.

Durante a cirurgia, as lesões da laringe são retiradas e enviadas para análise. Um fragmento dessa lesão será encaminhado para a pesquisa. Como as amostras serão colhidas durante sua cirurgia, isso não levará a riscos. Além disso, serão colhidos $4 \mathrm{~mL}$ de sangue que serão enviados ao laboratório. Esta coleta será feita durante o momento em que o anestesista pega a veia para a cirurgia. O único risco adicional é que, durante pegar essa veia, o local fique dolorido ou roxo. Os retornos após a cirurgia não dependerão da pesquisa, mas sim do tratamento da sua doença.

Podemos tirar qualquer dúvida sua. Não divulgaremos o seu nome em nenhum momento. Você não é obrigado(a) a fazer parte da pesquisa, e seu tratamento será o mesmo se não quiser participar. Você receberá uma via deste Termo de consentimento e poderá ter acesso aos resultados desta pesquisa

A aplicação deste termo e os esclarecimentos sobre o estudo serão sempre realizados pelo pesquisador.

Pesquisador responsável:

RODRIGO LACERDA NOGUEIRA

Telefone 16991862485

Nome:

Paciente

Data:

Nome:

Pesquisador

Data: 